

\section{Sumário}

Dossiê TEMÁTICO: NOVOS INSTITUTOS JURÍDICOS DE LICITAÇÕES E CONTRATOS 17

I. LicitaÇõEs E CONTRATOS PÚBLICOS: PARTE GERAL. 18

INTEGRATED CONTRACT IN LAW 14.133/2021: NEW LAW, SAME PROBLEMS? A STUDY OF COMPARATIVE LAW .20

Paulo Afonso Cavichioli Carmona, Bruno Ribeiro Marques e Odilon Cavallari

Reajustamento de preços na Nova Lei de Licitações e Contratos Administrativos BRASILEIRA: O "Princípio" Da ANUALIDAde.

Ricardo Silveira Ribeiro e Bráulio Gomes Mendes Diniz

A nova Lei de Licitações, as encomendas tecnológicas e o diálogo competitivo .61 André Dias Fernandes e Débora de Oliveira Coutinho

LiCITAÇÕES, CONTRATOS E O IMPULSO À APRENDIZAGEM PROFISSIONAL: UM ESTUDO SOBRE A CONTRATAÇÃo de APRENDizes no ESTAdo do AMAZONAS, BRAsIL

Emerson Victor Hugo Costa de Sá, Natasha Yasmine Castelo Branco Donadon e Mauro Augusto Ponce de Leão Braga

Licitações, contratos e Modelo Brasileiro de Processo: notas sobre a viabilidade DA UTILIZAÇÃo DE FERRAMENTAS PROCESSUAIS PARA CONFERIR MAIOR EFICIÊNCIA ÀS AQUISIÇÕES PÚBLICAS

Claudio Madureira e Carlos André Luís Araujo

RESOlUÇão DE CONFLITOS COM A ADMINISTRAÇÃo PÚBLICA E A NOVA LEI DE LICITAÇÕES E CONTRATOS: REFORÇO DOS MEIOS ALTERNATIVOS.

Clarissa Sampaio Silva e Danille Maia Cruz

A Adesão do Brasil ao Acordo sobre Contratações Públicas da OMC: entre tabus e DIFICULDADES REAIS

Eduardo Ferreira Jordã e Luiz Filippe Esteves Cunha

II. Accountability e controle

A LEI N. ${ }^{\circ}$ 14.133/2021 E OS NOVOS LIMITES do CONTROLE EXTERNO: A NECESSÁRIA DEFERÊNCIA dos Tribunais de Contas em prol da Administração Pública .................................. 162 Ricardo Schneider Rodrigues

O CONTROLE DAS CONTRATAÇÕES PÚBliCAS E A NOVA LEI DE LICITAÇÕES: O QUE HÁ DE Novo? 183

Leandro Sarai, Flávio Garcia Cabral e Cristiane Rodrigues Iwakura 
Programa de compliance como exigênCia em licitações: ANálises EM Prol da QUALIFICAÇÃo DO PROCESSO LICITATÓRIO NO CONTEXTO DA LEI 14.133/2021.

Cristian Ricardo Wittmann e Anayara Fantinel Pedroso

A NOVA REALIDAde bRASILEIRA DE NECESSIDADE DE PROGRAMAS DE INTEGRIDADE DAS PESSOAS JURÍDICAS LICITANTES EM PROCESSOS LICITATÓRIOS DA ADMINISTRAÇÃO PÚBLICA 227

Fernando Silva Moreira dos Santos e Luiz Fernando de Oriani e Paulillo

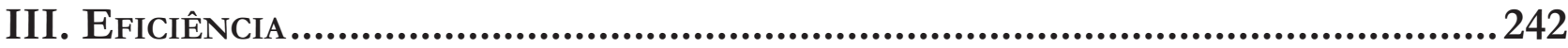

Efficiency contracts in the New Brazilian Procurement Law: conceptual FRAMEWORK AND INTERNATIONAL EXPERIENCE

Floriano de Azevedo Marques Neto, Hendrick Pinheiro e Tamara Cukiert

A gestão de riscos como instrumento para a aplicação efetiva do Princípio Constitucional dA EFICIÊNCIA.

Rafael Rabelo Nunes, Marcela Teixeira Batista Sidrim Perini e Inácio Emiliano Melo Mourão Pinto

IV. Contratação PÚblica No Direito ESTrangeiro

LA ADQUisición de VACUNAS CONTRA LA COVID-19 POR COLOMBIA: ENTRE LA CONFIDENCIALIDAD Y LA FALTA DE TRANSPARENCIA. 284

Gressy Kareny Rojas Cardona e David Mendieta

LA DISCRIMINACIÓN EX POST DE LOS OFERENTES DE UNA LICITACIÓN PÚBLICA COMO INFRACCIÓN ADMINISTRATIVA Y DE LIBRE COMPETÊNCIA 312 Jaime Arancibia Mattar

LA DISCRIMINACIÓN EX POST DE LOS OFERENTES DE UNA LICITACIÓN PÚBLICA COMO INFRACCIÓN ADMINISTRATIVA Y DE LIBRE COMPETÊNCIA..........................................................332 Udochukwu Uneke Alo, Obiamaka Adaeze Nwobu e Alex Adegboye

Outros Temas 348

I. Políticas públicas e institucionalidade

¿Existe El derecho humano a la identidad Cultural de los Migrantes en El Derecho INTERNACIONAL? 351 Juan Jorge Faundes e Glorimar Alejandra Leon Silva

El acceso a la justicia y el debido proceso ante el Tribunal Constitucional y la CorTe Suprema: dos NOCIONES DEL CONTENCIOSO ADMINISTRATIVO CHILENO .384 Pedro Harris Moya 
“Ministrocracia” E DECISÕES INDIVIDUAis CONTRAditórias No Supremo Tribunal FEDERAI

Ulisses Levy Silvério dos Reis e Emilio Peluso Neder Meyer

A POlÍtica de INOVAÇÃo COMO INSTRUMENTO DE REDUÇÃo DAS DESIGUALDADES REGIONAIS NO BRASIL

Caroline Viriato Memória e Uinie Caminha

Conflitos de Competência E A JudicializaÇão da Saúde no Federalismo Brasileiro.447 Jorge Leal Hanai, Luis Antônio Abrantes e Luiz Ismael Pereira

O Ministério Público no enfrentamento dos Reflexos da CRise da Covid-19: UMA

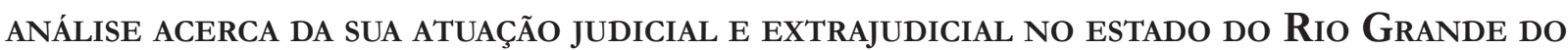
NorTE

Raquel Maria da Costa Silveira, Ana Mônica Medeiros Ferreira, Flávio Luiz Carneiro Cavalcanti e Haroldo Helinski Holanda

A CONSAgRaÇão CONSTITUCIONAL DA POlítica FALIMENTAR

Nuno de Oliveira Fernandes

II. Políticas públicas, grupos vulneráveis e litígios estruturais

LAS LIMITACIONES A LOS DERECHOS DE LOS GRUPOS VULNERABLES Y LOS SUJETOS DE ESPECIAL PROTECCIÓN DURANTE LA PANDEMIA Mary Luz Tobón Tobón

LitígIOS ESTRUTURAIS E A PROTEÇÃO DOS DIREITOS DOS POVOS INDÍGENAS DURANTE A PANDEMIA DE Covid-19: CONTRIBUições do ICCAL

Ana Carolina Lopes Olsen e Bianca M. Schneider van der Broocke

EPISTEMICÍDIO DAS NARRATIVAS NEGRAS E LITÍGIO ESTRUTURAL: INSTRUMENTOS EXTRAJUDICIAIS PARA DISSOLUÇÃO DO PROBLEMA NO SISTEMA EDUCACIONAL .......................................582

Vitor Fonsêca e Caroline da Silva Soares

Trajetórias E DiRETRIZES dAS POlíticas PÚbliCAS NACIONAIS PARA A POPULAÇão INFANTOJUVENIL EM SITUAÇÃO DE RUA...

Wânia Cláudia Gomes Di Lorenzo Lima, Cynthia Xavier de Carvalho e Maria Creusa de A. Borges

Emprendimiento como Fuente de Ingresos para las Víctimas del Conflicto Armado en el Marco de la Ley 1448 de Colombia. Reflexiones de la Implementación en el Valle del Cauca

Saulo Bravo García e Luz Marina Restrepo García

III. Políticas públicas e aÇão Restaurativa. 
JUSTIÇA RESTAURATIVA COMO AÇÃO COMUNICATIVA: EQUILÍBRIO ENTRE SISTEMA E MUNDO DA

Daniela Carvalho Almeida da Costa e Luciana Leonardo Ribeiro Silva de Araújo

JUSTIÇA RESTAURATIVA: ACORDOS E COOPERAÇÃO.................................................668

Samyle Regina Matos Oliveira e Selma Pereira de Santana 


\title{
Trajetórias e diretrizes das políticas públicas nacionais para a população infanto-juvenil em situação de rua*
}

\section{Pathways and guidelines of national public policies for children and adolescents in street situation}

\author{
Wânia Cláudia Gomes Di Lorenzo Lima** \\ Cynthia Xavier de Carvalho*** \\ Maria Creusa de A. Borges****
}

\section{Resumo}

A conjuntura de crianças e adolescentes em situação de rua é vista como uma violação flagrante dos direitos sociais, relacionados ao direito à vida, envolvendo direitos civis e políticos. Apesar de a elaboração de ações sistematizadas que integram as Políticas Públicas para essa população ser direcionada ao Estado, há um grande desafio em conectar as linhas de ação, criando projetos multifacetados de intervenções estatais. No presente artigo, investigam-se os programas e as propostas federais, com base nas normas vinculadas às políticas públicas para crianças e adolescentes em situação de rua, publicadas desde 2003. Realizou-se uma pesquisa bibliográfica de caráter histórico-normativa, com arcabouço analítico, por meio eletrônico e manual, em indexadores, portais, buscadores acadêmicos, bases de dados e visitas às bibliotecas virtuais. As normas vinculadas às políticas públicas para a população-alvo foram classificadas em cinco dimensões: econômica, educacional, sociofamiliar, integridade física e pessoal e selecionadas em torno de combinações de palavras-chave em blocos. Nos últimos anos, houve progresso relativo à criação de um sistema normativo voltado para a população em extrema pobreza. No entanto, o problema maior ainda se concentra na dificuldade de articulação entre as diversas demandas que emergem na realidade das ruas. Além disso, não há lei com conteúdo normativo explícito e sistêmico a qual envolva todas as dimensões e necessidades específicas para crianças e adolescentes em situação de rua.

Palavras-chaves: Bases normativas. Políticas públicas. Crianças e adolescentes. Situação de rua.

Doutorado em Sociologia pela UFPB.
Professora do Núcleo de Gestão, Universidade Federal de Pernambuco/Centro Acadêmico do Agreste (UFPE - CAA). Caruaru - PE, Brasil. E-mail: cynthia.carvalho@ufpe.br.

**** Doutorado em Sociologia pela UFPE. Professora do Departamento de Direito Privado do Centro de Ciências Jurídicas e Coordenadora do Programa de Pós-Graduação em Ciências Jurídicas (Mestrado e Doutorado em Direito) da Universidade Federal da Paraíba (UFPB). João Pessoa - PB, Brasil.

E-mail: mcaborges@gmail.com.

\section{Abstract}

The situation of children and adolescents living on the streets is seen as a flagrant violation of social rights, related to the right to life, involving civil and political rights. Despite being directed to the State to elaborate systematized actions that integrate Public Policies for this population, there is a great 
challenge in connecting the lines of action, creating multifaceted projects of State interventions. In this work, we highlight the historical-normative course of public policies since 2003, reviewing the norms linked to public policies for street children and adolescents. The focus was on federal programs and proposals, which were methodologically classified into five dimensions: economic, educational, socio-family, physical and personal integrity. The results showed that, in recent years, there has been progress in the creation of a normative system aimed at the population in extreme poverty, however the biggest problem still focuses on the difficulty of articulating the various demands that emerge in the reality of the streets. In addition, there is no law with explicit and systemic normative content that involves all the dimensions and specific needs studied in this work for street children and adolescents.

Keywords: Normative bases; Public policy; Children and adolescents; street situation

\section{Introdução}

A questão da "infância e juventude em situação de rua" deve ser colocada no centro do debate político-administrativo. Ela se manifesta por diferentes ângulos, demandando tutela do Estado por meio de ações individuais de proteção específica e controle jurisdicional das políticas públicas, decorrente da dimensão do direito ou interesse individual (ou coletivos).

As diretrizes e os objetivos das políticas públicas se concretizam pelo caráter diretivo dos programas governamentais, relativos à atribuição do Poder Executivo, mas cabe ao Poder Legislativo organizar, em leis de caráter geral e abstrato, a execução destas políticas. Goza o poder estatal executivo de liberdade discricionária para a aplicabilidade das políticas públicas, devido à variedade de condições administrativas para a sua execução. Se o foco da coletiva tem direitos reflexos de dimensão individual, necessita-se da sua jurisdicionalização, contribuindo para a ruptura da hegemonia real do Poder Executivo face à escolha de implantar ou não direitos sociais.

O estudo versa sobre o campo diferenciado de intervenção pública acerca de um universo específico da população — o problema de crianças e adolescentes em situação de rua. Foca-se nos fundamentos que norteiam as políticas adotadas no Brasil como instrumento de garantia dos direitos fundamentais de crianças e adolescentes em condição de vulnerabilidade. O objetivo é fornecer um panorama das bases normativas que integraram e integram as políticas e os programas lançados pelo Estado, em nível federal, destacando como tentaram alcançar a questão da situação de rua.

A tese levantada é a de que há um sistema normativo norteador de políticas públicas para a população em situação de rua, que atende crianças e adolescentes, no entanto, não articula os fatores multidimensionais que as envolvem, bem como é falho em proteção jurídica para a sua exigibilidade de implantação na gestão pública.

Visando atingir o objetivo, o estudo se baseia numa revisão bibliográfica com foco histórico, documental e normativo, de caráter analítico, com pesquisa realizada por meio eletrônico e manual em indexadores, portais governamentais, buscadores acadêmicos, bases de dados, revistas e bibliotecas virtuais.

Para tanto, parte-se da revisão das diretrizes federais nos documentos oficiais destinados às políticas públicas para a população de rua a partir de 2003. Abrange-se o período dos Governos Federais dos presidentes Luiz Inácio Lula da Silva, Dilma Rousseff, Michel Temer e do atual governo de Jair Messias Bolsonaro, compreendendo o cenário inicial da pandemia do novo Coronavírus.

Trabalham-se as legislações por meio de blocos temáticos, optando, didaticamente, pela construção de 05 dimensões: econômica, educacional, sociofamiliar, integridade física e pessoal, que serão descritas no transcorrer desse trabalho. Consideram-se, para referência conceitual, crianças e adolescentes em situação 
de rua que já tiveram vínculos familiares fragilizados ou rompidos e que possuem, na rua, mesmo transitória, uma relação como espaço de moradia e referência no seu cotidiano social. A análise da categoria "intervenção estatal" concentra-se em entender o significado das políticas públicas para crianças e adolescentes em condição de vulnerabilidade, bem como o contexto em que se apresenta na estrutura do Estado, na edificação da proteção e na organização do direito infanto-juvenil.

\section{2 políticas para crianças e adolescentes em situação de rua}

A situação de rua é um retrato do descompasso entre a garantia de direitos normatizados no Brasil e a efetivação deles, visivelmente violando princípios constitucionais. Quando se chega a uma política estatal de institucionalização com crianças e adolescentes, anteriormente, houve falhas na inserção ou ausência de políticas públicas para a construção da cidadania, voltadas para o convívio familiar e para inserção social.

As políticas públicas são instrumentos previstos no Sistema de Garantias de Direitos da Criança e do Adolescente para atuação estatal como assegurador dos direitos fundamentais, tendo como pilar o olhar da Proteção Integral. Para Mônica Leal', elas são "instrumentos de atuação (política) voltados à realização dos direitos fundamentais (jurídicos)", dados por opções políticas, associadas à noção de discricionariedade.

O ponto chave se concentra como uma opção para realização de determinados fins: os direitos fundamentais. Segundo Petri ${ }^{2}$ as políticas públicas são diretrizes para ações de indivíduos, organizações e Estado e devem ser entendidas como um conjunto de processos que culminam na escolha racional e coletiva de prioridades, para definição dos interesses públicos reconhecidos pelo direito. Canela Júnior ${ }^{3}$ as define como todos os atos legislativos e administrativos necessários à satisfação espontânea dos direitos econômicos e sociais. Pousa Júnior ${ }^{4}$, ao tratar de crianças e adolescentes como pessoas em situação de rua, divide os programas sociais em:

políticas desenvolvimentistas, que se concentram nas políticas de crescimento econômico e social do país, entra aqui a luta contra a pobreza; políticas emancipatórias, também desencadeadas a partir de políticas voltadas para a superação da pobreza, exigem novos arranjos institucionais capazes de promover a articulação entre políticas setoriais e formas mais amplas de participação do público; política redistributiva, se dividem em políticas estruturais e compensatórias, a primeira combina as políticas a partir da redistribuição de ativos (acesso ao crédito, impacto a longo e médio prazo), enquanto as compensatórias corrigem temporariamente, a posteriori com impacto de curto prazo. ${ }^{5}$

Não se tem como pensar nos problemas da infância e juventude sem analisar a estrutura de ações das políticas públicas e a responsabilidade do Poder Estatal para a criação de espaço que viabilize a formulação e controle, por meio da participação popular na gestão administrativa. Para Rizzini, Noiffe e Baptista ${ }^{6}$, o Estatuto da Criança e do Adolescente (ECA) entende que ambos devam estar assegurados por políticas de proteção, promoção e direitos, bem como as suas respectivas famílias.

1 LEAL, Mônica Clarissa Henning. A dignidade humana e o princípio da proporcionalidade como fundamentos e como parâmetro para o controle jurisdicional de políticas públicas. In: ALEXY, Robert; BAEZ, Narcisio Leandro Xavier; SILVA, Rogério Luiz Nery. Dignidade Humana, direitos sociais e não-positivismos incluso. Florianópolis: Qualis, 2015; pág. 144.

2 PETRI, Maria José Constantino. O direito das crianças e adolescentes à convivência familiar e comunitária: responsabilidade da família, da comunidade e do estado. Tese - Programa de Pós-Graduação em Direito da Universidade de São Paulo, São Paulo, 2008.

3 CANELA JÚNIOR, Osvaldo. A efetivação dos direitos fundamentais através do direito coletivo: o âmbito de cognição das políticas públicas pelo poder judiciário. Tese - Programa de pós-graduação em Direito, Universidade de São Paulo, 2009.

4 POUSA JÚNIOR, Efren Fernandez. População em situação de rua: perspectivas atuais no resgate da cidadania e reinserção social. Dissertação - Programa de Pós-Graduação em Direito Político e Econômico, Universidade Presbiteriana Mackenzie, São Paulo, 2012.

5 POUSA JÚNIOR, Efren Fernandez. População em situação de rua: perspectivas atuais no resgate da cidadania e reinserção social. Dissertação - Programa de Pós-Graduação em Direito Político e Econômico, Universidade Presbiteriana Mackenzie, São Paulo, 2012 ; pág. 13.

6 RIZZINI, Irene; NOIFFE, Luciana; BAPTISTA, Rachel. Experiência de promoção do direito à convivência familiar e comunitária no Brasil. São Paulo: Cortez, 2006. 
O próprio $\mathrm{ECA}^{7}$, ao discorrer sobre diretrizes da política de atendimento, determina a descentralização administrativa, municipalização das ações e participação popular na formulação, controle e fiscalização das políticas, por intermédio dos conselhos dos direitos da criança e do adolescente nos três níveis da federação: Conselho Municipal dos Direitos da Criança e do Adolescente (CMDCA), Conselho Estadual dos Direitos da Criança e do Adolescente (CONDECA) e Conselho Nacional dos Direitos da Criança e do Adolescente (CONANDA). Esses órgãos são colegiados, permanentes, de caráter deliberativo e composição paritária e de gestores de políticas públicas, previstos na Lei n. ${ }^{\circ}$ 8.242/91, fundamentais na elaboração de políticas destinadas à condição de vulnerabilidade.

Ao interpretar os artigos 87 e 88 do ECA, alterados pela Lei n. ${ }^{\circ} 13.257$, de $2016^{8}$, verifica-se a manutenção de fundos orçamentários dos conselhos, e também se projeta um sistema articulado, com criação de programas descentralizados político-administrativos referentes à garantia das políticas sociais básicas e programas especializados, destinados à proteção especial.

Enquanto os Conselhos são responsáveis pela definição da política de atendimento e controle do orçamento, em conexão com as políticas de Assistência Social, o Estatuto institui Conselhos Tutelares (CT) com papel de zelar, para que as medidas de proteção, apoio e orientação às crianças e adolescentes sejam cumpridas 9 .

As demandas da população em situação de rua geram a necessidade de diversos focos interligados, visando cessar as privações básicas. Para Petri ${ }^{10}$, as políticas públicas se exteriorizam por meio de planos, que podem ser de caráter geral (como o Plano Nacional de Saúde ou o Plano de Educação) ou específico (quando foca na violência sexual, na população de rua...). O instrumento normativo do plano é a lei, em que se estabelecem objetivos, instrumentos institucionais e condições para implementação.

Com a Constituição Federal (CF) de 1988 e a criação do ECA, o atendimento à criança e ao adolescente alterou-se significativamente, em especial no que diz respeito à inserção dos diplomas legais complementares para efetivação das políticas públicas. Em relação à assistência social, a CF, por meio do art. 194, qualificou, em relação à seguridade social, e, para referendar o texto constitucional, no ano de 1993, a Lei Orgânica da Assistência Social (LOAS), alterada pela Lei n. ${ }^{\circ} 12.435$ de 2011, definiu o Sistema Único de Assistência Social (SUAS).

De acordo com essa legislação, há delimitação material entre os três entes federativos para efetivação das políticas públicas. Para Strapasson e Pamplona ${ }^{11}$, a LOAS define a competência municipal para a execução de projetos de enfrentamento à pobreza e ações assistenciais emergenciais. Sendo assim, o poder público municipal passou a ter a tarefa de manter serviços e programas de atenção à população de rua, garantindo padrões básicos de dignidade e não violência para a concretização de mínimos sociais e dos direitos de cidadania.

No ano de 2005, o art. 23 da LOAS foi alterado por meio da Lei n. ${ }^{\circ} 11.258$, incluindo, na organização de serviços da Assistência Social, a necessidade de programas de amparo: “[...] às crianças e adolescentes em situação de risco pessoal e social, em cumprimento ao disposto no art. 227 da CF e na Lei n. ${ }^{\circ}$ 8.069, de 13 de julho de 1990 [...] às pessoas que vivem em situação de rua"12. A articulação da saúde com a assistência

\footnotetext{
7 BRASIL. Lei Federal n ${ }^{\circ}$ 8.069, de 19 de setembro de 1990. Brasília, 1990.

8 BRASIL. Lei Federal n ${ }^{\circ}$ 13.257, de 08 de março de 2016. Brasília, 2016a.

9 FONSECA, Franciele Fagundes et al. As vulnerabilidades na infância e adolescência e as políticas públicas brasileiras de intervenção. Revista Paul Pediatria, v. 31, n. 2, p. 258-64, 2013. Disponível em: <www.scielo.br/pdf/rpp/v31n2/19.pdf> Acesso em: 18 jul. 2016.

${ }^{10}$ PETRI, Maria José Constantino. O direito das crianças e adolescentes à convivência familiar e comunitária: responsabilidade da família, da comunidade e do estado. Tese - Programa de Pós-Graduação em Direito da Universidade de São Paulo, São Paulo, 2008.

11 STRAPASSON, Karoline; PAMPLONA, Danielle Anne. O direito em contradição: direitos humanos, atuação estatal e população em situação de rua. Revista Política Pública, São Luís, v. 18, n. 2, p. 439-456, jul./dez. 2014.

12 BRASIL. Lei Federal n. ${ }^{\circ} 11.258$, de 30 de dezembro de 2005. Brasília, 2005.
} 
social é fundamental para o atendimento a essa população. A Lei Orgânica de Saúde (LOS), Lei n. ${ }^{\circ}$ 8.080, de 28/12/1990, estabelece como dever do Estado assegurar a universalidade do acesso à saúde por políticas que promovam a integralidade de assistência com vista à sua promoção, proteção e recuperação ${ }^{13}$.

Outros marcos normativos impulsionaram políticas destinadas à população infanto-juvenil em situação de rua: o Estatuto da Juventude, Lei n.. 12.852, de 05/08/2013 ${ }^{14}$; Lei Brasileira de Inclusão da Pessoa com Deficiência (Estatuto da Pessoa com Deficiência), de 06/07/2015 ${ }^{15}$; Lei de Políticas Públicas para a Primeira Infância, Lei n. ${ }^{\circ} 13.257$, de 08/03/2016 ${ }^{16}$.

Entrecruzam o contexto das crianças e adolescentes em situação de rua vários documentos de políticas públicas e legislações, que serão alocados em cinco dimensões (quadro 2), conforme as maiores necessidades desse público. O objetivo é abordar, didaticamente, os documentos que podem dar legitimidade à intervenção estatal. Destaca-se que essas dimensões não têm perfeita distinção entre elas.

Quadro 1- dimensões conforme as necessidades de crianças e adolescentes em situação de rua ${ }^{17}$

\begin{tabular}{|l|l|}
\hline Dimensões & Abrangência \\
\hline Da pessoa & $\begin{array}{l}\text { Legislações mais gerais voltadas para o contexto da criança e do adolescente ou para a } \\
\text { população de rua. Na impossibilidade de identificar a linha de diretriz básica que carac- } \\
\text { teriza a ação principal, mas podendo identificar objetivamente a população-alvo, essas } \\
\text { legislações serão categorizadas na Dimensão Pessoa. }\end{array}$ \\
\hline Econômica & $\begin{array}{l}\text { Remete a recursos financeiros voltados para manutenção individual ou melhoria da ren- } \\
\text { da doméstica, reparação econômica dessa população. Pode incluir, ainda, proposta com } \\
\text { extensão macro de combate à pobreza, voltada ao desenvolvimento econômico do país, } \\
\text { além de formas de financiamento para ações sociais que envolvam a população em situa- } \\
\text { ção de rua. }\end{array}$ \\
\hline Educacional & $\begin{array}{l}\text { Alcança as ações de inserção dessa população na educação básica e/ou no ensino pro- } \\
\text { fissionalizante. Projetos que viabilizem a inserção da criança na escola ou de criação de } \\
\text { novos modelos de escola para as crianças e adolescentes em situação de rua. Agrupam-se } \\
\text { os guias de orientações técnicas, por tais documentos terem finalidade educacional para a } \\
\text { construção de serviços de atendimento a essa população. }\end{array}$ \\
\hline $\begin{array}{l}\text { Integridade } \\
\text { física }\end{array}$ & $\begin{array}{l}\text { Remete ao bem-estar e à saúde física da população de rua, com projetos que viabilizam } \\
\text { saúde, alimentação e moradia. }\end{array}$ \\
\hline Sociofamiliar & $\begin{array}{l}\text { Abarca propostas de reintegração às famílias. Contempla não somente o retorno às famí- } \\
\text { lias, mas também a criação de novos laços em múltiplos arranjos familiares e em acolhi- } \\
\text { mento institucional temporário. }\end{array}$ \\
\hline
\end{tabular}

A seguir (quadro 2), as legislações para criança e adolescente em situação de rua foram reunidas em grupos de dimensões, sendo cada eixo referencial para o estudo.

\footnotetext{
13 BRASIL. Lei Federal n. ${ }^{\circ}$ 8.080, de 19 de setembro de 1990. Brasília, 1990b.

14 BRASIL. Lei Federal n. ${ }^{0}$ 12.852, de 05 de agosto de 2013. Brasília, 2013a.

15 BRASIL. Lei Federal n. ${ }^{0} 13.146$, de 06 de julho de 2015. Brasília, 2015.

16 BRASIL. Lei Federal n. ${ }^{\circ}$ 13.257, de 08 de março de 2016. Brasília, 2016a.

17 LIMA, Wânia C. G. Di Lorenzo. Crianças e adolescentes em situação de rua: propostas pedagógicas como instrumento de materialização do direito ao desenvolvimento. In: BORGES, Maria C. Araújo; SANCHES, Samyra H. Dal Farra Naspolini. Direito, Educação, Ensino e Metodologia Jurídicos I (Recurso eletrônico on-line). Florianópolis: CONPEDI, 2014. Disponível em: http://publicadireito.com.br/artigos/?cod=a3e8b5e0becdbfb1. Acesso em: 20 jul. 2015.
} 
Quadro 2 - documentos direcionadores das políticas públicas e suas dimensões ${ }^{18}$

\begin{tabular}{|c|c|c|}
\hline LEGISLAÇÃO / DATA & CONTEÚDO & DIMENSÃO \\
\hline $\begin{array}{l}\text { Lei n. }{ }^{\circ} 10.836 / 2004 \text { / Data: } \\
\text { 09/01/2004. }\end{array}$ & Programa Bolsa-Família (PBF). & Econômica \\
\hline $\begin{array}{l}\text { Lei n. }{ }^{\circ} 11.258 \text { que alterou o art. } \\
23 \text { da Lei no } 8.742 / 1993 \text { / Data: } \\
30 / 12 / 2005 .\end{array}$ & $\begin{array}{l}\text { Inclui na LOAS a previsão expressa de pro- } \\
\text { gramas para população em situação de rua na } \\
\text { política de Assistência Social. }\end{array}$ & Pessoa \\
\hline $\begin{array}{l}\text { Ministério do Desenvolvimento } \\
\text { Social e Combate à Fome / Data: } \\
\text { 12/2006. }\end{array}$ & $\begin{array}{l}\text { Plano Nacional de Promoção, Proteção e De- } \\
\text { fesa do Direito de Crianças e Adolescentes à } \\
\text { Convivência Familiar e Comunitária. }\end{array}$ & Sociofamiliar \\
\hline $\begin{array}{l}\text { Ministério do Desenvolvimento } \\
\text { Social e Combate à Fome / Data: } \\
06 / 2009 \text {. }\end{array}$ & $\begin{array}{l}\text { Orientações Técnicas para os Serviços de aco- } \\
\text { lhimento para Crianças e Adolescentes. }\end{array}$ & Sociofamiliar \\
\hline $\begin{array}{l}\text { Resolução n. }{ }^{\circ} 109 / 2009 \text { do Con- } \\
\text { selho Nacional de Assistência Social } \\
\text { (CNAS) / Data: } 11 / 11 / 2009 \text {. }\end{array}$ & $\begin{array}{l}\text { Centro de Referência Especializado para Po- } \\
\text { pulação em Situação de Rua (Centro POP). } \\
\text { (Previsão no art. } 7^{\circ} \text { do Decreto n. }{ }^{\circ} 7.053 \text { de } \\
23 \text { de dezembro de 2009). }\end{array}$ & Pessoa \\
\hline $\begin{array}{l}\text { Decreto Presidencial n. }{ }^{\circ} 7.053 / \\
\text { Data: } 23 / 12 / 2009 .\end{array}$ & $\begin{array}{l}\text { Política Nacional para Inclusão Social da Po- } \\
\text { pulação de Rua. }\end{array}$ & Pessoa \\
\hline $\begin{array}{l}\text { Portaria n. }{ }^{\circ} 3.305 / 09-\text { Ministério } \\
\text { da Saúde / Data: 24/12/2009. }\end{array}$ & $\begin{array}{l}\text { Comitê Técnico de Saúde da População em } \\
\text { Situação de Rua. }\end{array}$ & $\begin{array}{l}\text { Integridade } \\
\text { física }\end{array}$ \\
\hline $\begin{array}{l}\text { Rede Nacional Primeira Infância } \\
\text { (RNPI) - CONANDA / Data: } \\
\text { aprovado em dezembro de 2010; revi- } \\
\text { sado e atualizado em } 2020 \text {. }\end{array}$ & Plano Nacional Primeira Infância (PNPI). & Pessoa \\
\hline $\begin{array}{l}\text { Portaria n. }{ }^{\circ} 843 \text { - Ministério de } \\
\text { Estado do Desenvolvimento So- } \\
\text { cial e Combate à Fome / Data: } \\
28 / 12 / 2010 .\end{array}$ & $\begin{array}{l}\text { Dispõe sobre o cofinanciamento federal, por } \\
\text { meio do Piso Fixo de Média Complexidade } \\
\text { - PFMC, dos serviços socioassistenciais ofer- } \\
\text { tados pelos Centros de Referência Especiali- } \\
\text { zados de Assistência Social - CREAS e pelos } \\
\text { Centros de Referência Especializados para } \\
\text { População em Situação de Rua. }\end{array}$ & Econômica \\
\hline $\begin{array}{l}\text { Orientações Técnicas - Secretaria } \\
\text { Nacional de Renda e Cidadania e Se- } \\
\text { cretaria Nacional de Assistência So- } \\
\text { cial; Ministério do Desenvolvimento } \\
\text { Social e Combate à Fome - MDS / } \\
\text { Data: } 29 / 11 / 2011 \text {. }\end{array}$ & $\begin{array}{l}\text { Orientações Técnicas: Centro de Referência } \\
\text { Especializado para População em Situação } \\
\text { de Rua - Centro POP, SUAS e População em } \\
\text { Situação de Rua. Volume } 3 .\end{array}$ & Educacional \\
\hline $\begin{array}{l}\text { Portaria n. }{ }^{\circ} 122 \text { - Ministério da Saú- } \\
\text { de / Data: 05/11/2011. }\end{array}$ & Programa Consultório de Rua. & $\begin{array}{l}\text { Integridade } \\
\text { física }\end{array}$ \\
\hline
\end{tabular}

\footnotetext{
18 LIMA, Wânia C. G. Di Lorenzo; BORGES, Maria C. de Araújo. Crianças e adolescentes em situação de rua: propostas pedagógicas como instrumento de materialização do direito ao desenvolvimento. In: BORGES, Maria C. Araújo; SANCHES, Samyra H. Dal Farra Naspolini. Direito, Educação, Ensino e Metodologia Jurídicos I (Recurso eletrônico on-line). Florianópolis: CONPEDI, 2014. Disponível em: <http://publicadireito.com.br/publicacao/ufpb/livro.php?gt=264> Acesso em: 20 jul. 2015.
} 


\begin{tabular}{|c|c|c|}
\hline LEGISLAÇÃO / DATA & CONTEÚDO & DIMENSÃO \\
\hline $\begin{array}{l}\text { Ministério da Saúde - Secretaria } \\
\text { de Atenção Básica à Saúde - Depar- } \\
\text { tamento de Atenção Básica/ Data: } \\
2012 .\end{array}$ & $\begin{array}{l}\text { Manual sobre Cuidado à Saúde junto à Popu- } \\
\text { lação em Situação de Rua. }\end{array}$ & $\begin{array}{l}\text { Integridade } \\
\text { física }\end{array}$ \\
\hline $\begin{array}{l}\text { Portaria n. } .^{\circ} 595 \text { - Ministério das } \\
\text { Cidades / Data: 12/2013. }\end{array}$ & $\begin{array}{l}\text { Define a população em situação de rua como } \\
\text { alvo prioritário para participar de programas } \\
\text { de habitação, como o "Minha Casa Minha } \\
\text { Vida". }\end{array}$ & $\begin{array}{l}\text { Integridade } \\
\text { física }\end{array}$ \\
\hline $\begin{array}{l}\text { Resolução } \text { n. }^{\circ} 2 \text { - Ministério da } \\
\text { Saúde - Secretaria de Gestão Es- } \\
\text { tratégica e Participativa / Data: } \\
27 / 02 / 2013 \text {. }\end{array}$ & $\begin{array}{l}\text { Plano Operativo para Implementação de } \\
\text { Ações em Saúde da População em Situação de } \\
\text { Rua. }\end{array}$ & $\begin{array}{l}\text { Integridade } \\
\text { física }\end{array}$ \\
\hline $\begin{array}{l}\text { Portaria n. } 35 \text { - Ministério do De- } \\
\text { senvolvimento Social e Combate à } \\
\text { Fome / Data: 23/04/2014. }\end{array}$ & $\begin{array}{l}\text { Altera a Portaria n. }{ }^{\text {o }} 843 \text {, de } 28 \text { de dezembro } \\
\text { de } 2010 \text {, do Ministério do Desenvolvimento } \\
\text { Social e Combate à Fome, que dispõe sobre } \\
\text { o cofinanciamento federal, por meio do Piso } \\
\text { Fixo de Média Complexidade - PFMC, dos } \\
\text { serviços socioassistenciais ofertados pelos } \\
\text { Centros de Referência Especializados de As- } \\
\text { sistência Social - Creas e pelos Centros de } \\
\text { Referência Especializados para População em } \\
\text { Situação de Rua. }\end{array}$ & Econômica \\
\hline $\begin{array}{l}\text { Portaria n. }{ }^{\circ} 693 \text { - Secretaria de Di- } \\
\text { reitos Humanos da Presidência da } \\
\text { República / Data: 25/11/214. }\end{array}$ & $\begin{array}{l}\text { Estabelece regras e critérios de execução e } \\
\text { monitoramento do Programa Nacional de } \\
\text { Acesso ao Ensino Técnico e Emprego no } \\
\text { âmbito da Secretaria de Direitos Humanos da } \\
\text { Presidência da República - Pronatec Direitos } \\
\text { Humanos. }\end{array}$ & Educação \\
\hline $\begin{array}{l}\text { Decreto } \text { n. }^{\circ} 7.492 / 11 \text {, alterado pelo } \\
\text { Decreto } 8.794 \text { / Data: 02/06/2011. }\end{array}$ & Plano Brasil sem Miséria. & Econômica \\
\hline $\begin{array}{l}\text { Resolução Conjunta n. }{ }^{\circ} 1 \text { do } \\
\text { CNAS/CONANDA / Data: } \\
\text { 15/12/2016. }\end{array}$ & $\begin{array}{l}\text { Dispõe sobre o conceito e o atendimento de } \\
\text { criança e adolescente em situação de rua e in- } \\
\text { clui o subitem 4.6, no item 4, do Capítulo III } \\
\text { do documento Orientações Técnicas: Serviços } \\
\text { de Acolhimento para Crianças e Adolescentes. }\end{array}$ & Pessoa \\
\hline $\begin{array}{l}\text { Resolução n. }^{\circ} 173 \text { - CONANDA. } \\
\text { Grupo de Trabalho - Crianças e } \\
\text { adolescentes em situação de rua do } \\
\text { CONANDA - Campanha nacional de } \\
\text { enfrentamento à situação de moradia } \\
\text { nas ruas de crianças e adolescentes / } \\
\text { Data: } 10 / 2017 .\end{array}$ & $\begin{array}{l}\text { Diretrizes nacionais para o atendimento a } \\
\text { crianças e adolescentes em situação de rua. }\end{array}$ & Pessoa \\
\hline
\end{tabular}




\begin{tabular}{|c|c|c|}
\hline LEGISLAÇÃO / DATA & CONTEÚDO & DIMENSÃO \\
\hline $\begin{array}{l}\text { Resolução n. }{ }^{\circ} 31 \text { - Comissão Inter- } \\
\text { gestores Tripartite - Ministério da } \\
\text { Saúde. Data: 30/ 11/ } 2017 .\end{array}$ & $\begin{array}{l}\text { Dispõe sobre o II Plano Operativo (2017- } \\
\text { 2019) das ações de saúde previstas na Política } \\
\text { Nacional para a População em Situação de } \\
\text { Rua no âmbito do Sistema Único de Saúde } \\
\text { (SUS). }\end{array}$ & $\begin{array}{l}\text { Integridade } \\
\text { Física }\end{array}$ \\
\hline $\begin{array}{l}\text { Decreto n.o } 9.894 \text { / Data: } \\
\text { 27/06/2019. }\end{array}$ & $\begin{array}{l}\text { Dispõe sobre o Comitê Intersetorial de Acom- } \\
\text { panhamento e Monitoramento da Política Na- } \\
\text { cional para a População em Situação de Rua. }\end{array}$ & Pessoa \\
\hline $\begin{array}{l}\text { Portaria } \text { n. }^{\circ} 1.553 \text { - Ministério da } \\
\text { Saúde / Gabinete do Ministro / } \\
\text { Data: 01/07/2019. }\end{array}$ & $\begin{array}{l}\text { Credencia Municípios a receberem incentivos } \\
\text { financeiros referentes às equipes de Consultó- } \\
\text { rio na Rua (eCR). }\end{array}$ & $\begin{array}{l}\text { Integridade } \\
\text { física }\end{array}$ \\
\hline $\begin{array}{l}\text { Lei n. }^{\circ} 13.982 \text { - Altera a Lei n. } \\
\text { 8.742, de 07/12/1993 / Data: } \\
\text { 02/04/2020. }\end{array}$ & $\begin{array}{l}\text { Dispõe sobre parâmetros adicionais de ca- } \\
\text { racterização da situação de vulnerabilidade } \\
\text { social para fins de elegibilidade ao benefício de } \\
\text { prestação continuada (BPC) e estabelece me- } \\
\text { didas excepcionais de proteção social a serem } \\
\text { adotadas durante o período de enfrentamento } \\
\text { da emergência de saúde pública de importân- } \\
\text { cia internacional decorrente do Coronavírus } \\
\text { (Covid-19). }\end{array}$ & Econômica \\
\hline $\begin{array}{l}\text { Decreto } .^{\circ} 10.316 \text {, que regulamenta } \\
\text { a Lei n. }{ }^{\circ} 13.982 \text {, de } 02 / 04 / 2020 / \\
\text { Data: } 07 / 04 / 2020 .\end{array}$ & $\begin{array}{l}\text { Estabelece medidas excepcionais de proteção } \\
\text { social a serem adotadas durante o período de } \\
\text { enfrentamento da emergência de saúde públi- } \\
\text { ca de importância internacional decorrente do } \\
\text { Coronavírus (Covid-19). }\end{array}$ & Econômico \\
\hline $\begin{array}{l}\text { Portaria n. }{ }^{\circ} 04 \text { - Ministério da Ci- } \\
\text { dadania / Secretaria Especial do De- } \\
\text { senvolvimento Social/Secretaria Na- } \\
\text { cional de Assistência Social / Data: } \\
\text { 22/10/2020. }\end{array}$ & $\begin{array}{l}\text { Orientações técnicas em conjunto para a atua- } \\
\text { ção intersetorial e integrada entre a rede so- } \\
\text { cioassistencial e as Comunidades Terapêuticas } \\
\text { no enfrentamento da pandemia causada pelo } \\
\text { Coronavírus (Covid-19), juntamente à popu- } \\
\text { lação em situação de rua, usuária abusiva de } \\
\text { substâncias psicoativas. }\end{array}$ & Pessoa \\
\hline $\begin{array}{l}\text { Portaria n. }{ }^{\circ} 54 \text { - Ministério da Cida- } \\
\text { dania / Secretaria Especial do Desen- } \\
\text { volvimento Social / Secretaria Na- } \\
\text { cional de Assistência Social / Data: } \\
01 / 04 / 2020 .\end{array}$ & $\begin{array}{l}\text { Recomendações gerais aos gestores e traba- } \\
\text { lhadores do Sistema Único de Assistência } \\
\text { Social (SUAS) dos Estados, Municípios e do } \\
\text { Distrito Federal, com o objetivo de garantir a } \\
\text { continuidade da oferta de serviços e atividades } \\
\text { essenciais da Assistência Social, com medidas } \\
\text { e condições que garantam a segurança e a saú- } \\
\text { de dos usuários e profissionais do SUAS, no } \\
\text { enfrentamento da emergência de saúde pú- } \\
\text { blica decorrente do Coronavírus (Covid-19), } \\
\text { no âmbito do Sistema Único de Assistência } \\
\text { Social. }\end{array}$ & $\begin{array}{l}\text { Integridade } \\
\text { Física }\end{array}$ \\
\hline
\end{tabular}




\begin{tabular}{|c|c|c|}
\hline LEGISLAÇÃO / DATA & CONTEÚDO & DIMENSÃO \\
\hline $\begin{array}{l}\text { Portaria } \text { n. }^{\circ} 69 \text { - Secretaria Nacio- } \\
\text { nal de Assistência Social / Data: } \\
\text { 14/05/2020. }\end{array}$ & $\begin{array}{l}\text { Recomendações gerais para a garantia de pro- } \\
\text { teção social à população em situação de rua, } \\
\text { inclusive imigrantes, no contexto da pandemia } \\
\text { do novo Coronavírus (Covid-19). }\end{array}$ & Pessoa \\
\hline $\begin{array}{l}\text { Portaria n. }{ }^{\circ} 369-\text { Ministério da } \\
\text { Cidadania / Gabinete do Ministro / } \\
\text { Data: 29/04/2020. }\end{array}$ & $\begin{array}{l}\text { Dispõe acerca do atendimento do Cadastro } \\
\text { Único para Programas Sociais do Governo } \\
\text { Federal - Cadastro Único, disposto pelo De- } \\
\text { creto n. }{ }^{\circ} \text { 6.135, de } 26 \text { de junho de } 2007 \text {, no } \\
\text { Distrito Federal e nos municípios que estejam } \\
\text { em estado de calamidade pública ou em situa- } \\
\text { ção de emergência reconhecidos pelos gover- } \\
\text { nos estadual, municipal, do Distrito Federal ou } \\
\text { federal, inclusive a Emergência de Saúde Pú- } \\
\text { blica de Importância Internacional declarada } \\
\text { pela Organização Mundial da Saúde, em } 30 \text { de } \\
\text { janeiro de 2020, em decorrência da Infecção } \\
\text { Humana pelo novo Coronavírus (Covid-19). }\end{array}$ & Econômica \\
\hline $\begin{array}{l}\text { Resolução n. }{ }^{\text {o }} 40 \text { - Ministério da } \\
\text { Mulher, da Família e dos Direitos Hu- } \\
\text { manos / Conselho Nacional dos Di- } \\
\text { reitos Humanos / Data: } 13 / 10 / 2020 .\end{array}$ & $\begin{array}{l}\text { Dispõe sobre as diretrizes para promoção, } \\
\text { proteção e defesa dos direitos humanos das } \\
\text { pessoas em situação de rua, de acordo com a } \\
\text { Política Nacional para População em Situação } \\
\text { de Rua. }\end{array}$ & Pessoa \\
\hline $\begin{array}{l}\text { Recomendação conjunta n. } .^{\circ} 1 \text { - } \\
\text { Conselho Nacional de Justiça; Conse- } \\
\text { lho Nacional do Ministério Público, } \\
\text { Ministério da Cidadania, Ministério } \\
\text { da Mulher, da Família e dos Direitos } \\
\text { Humanos / Data: } 16 / \text { 05/ } 2020 .\end{array}$ & $\begin{array}{l}\text { Dispõe sobre cuidados a crianças e adolescen- } \\
\text { tes com medida protetiva de acolhimento, no } \\
\text { contexto de transmissão comunitária do novo } \\
\text { Coronavírus (Covid-19), em todo o território } \\
\text { nacional e dá outras providências. }\end{array}$ & Sociofamiliar \\
\hline
\end{tabular}

Atualizado pelas autoras (2021)

Tais dimensões se correlacionam, criando tensões para assumir o perfil de sua cobertura. Com base nos problemas e características que afetam a população foco, discute-se a abrangência das legislações por blocos, isso porque o quadro mostra que alguns programas elaborados pelos últimos governos se destinaram diretamente à população em situação de rua, outros voltaram-se para o contexto de desenvolvimento infanto-juvenil. Ainda, constata-se uma política de geração de renda como estratégia de intervenção de combate ao ciclo da pobreza. Recentemente, têm-se também vinculado as políticas emergenciais de caráter geral, focadas nos efeitos da situação pandêmica, mas com alcance à população em situação de rua. Para facilitar a análise desse contexto, o próximo item inicia-se pelo percurso normativo da dimensão pessoa.

\subsection{Dimensão da pessoa}

A CF, no seu artigo 203, reconhece a Assistência Social como política pública, direito do cidadão e dever do Estado, além de garantir a universalização dos direitos sociais. Em sintonia com a CF, a LOAS, modificada pela Lei n. ${ }^{\circ} 11.258 / 2005$, trouxe o cenário das ruas para a organização da Assistência Social, determinando, por meio do art. 23, a criação de programas de amparo, tanto para crianças e adolescentes em situação de risco pessoal e social como, especificamente, para as pessoas em situação de rua. O direito 
à assistência social, por meio da proteção social, é constitucional e previsto no artigo 203, I, para todos que dele necessitem.

O guia de atuação ministerial em defesa dos direitos das pessoas em situação de rua conclui que a assistência social deverá ser prestada a todos os que dela necessitarem, para a provisão dos mínimos sociais e o atendimento às necessidades básicas de que tratam a CF e a LOAS. Mínimo existencial é tratado como "um conjunto de fatores e direitos que são condições para uma existência digna"; qualquer omissão ou insuficiência na oferta de serviços que garantam o mínimo existencial é violação do dever do Estado de promover a dignidade da pessoa humana.

Acrescenta-se ao Sistema Brasileiro de Proteção Social (SBPS) a Política Nacional para Inclusão Social da População de Rua (Decreto Presidencial n. ${ }^{\circ}$ 7.053/2009), que, além de prever a criação de Centros de Referência, com avanço na criação de redes de acolhimento temporário, estabeleceu diretrizes da atuação governamental para essa população.

A Política Nacional para Inclusão Social previu a criação de política de atendimento temporário integrada ao SUAS, cabendo ao Ministério do Desenvolvimento Social e Combate à Fome (MDS) — atualmente incorporado ao Ministério da Cidadania - promover a reestruturação e ampliação da rede de acolhimento com transferência de recursos aos municípios, Estados e Distrito Federal. Tal política é estabelecida por serviços municipais especializados em abordagem social, instalados nos Centro de Referência Especializado para População em Situação de Rua (Centro POP) e Centro de Referência Especializado da Assistência Social (CREAS). Esses são unidades de Proteção Social Especializada (PSE) de Média Complexidade, de natureza pública e estatal, as quais ofertam serviço para pessoas que utilizam as ruas como espaço de moradia/ sobrevivência. Segundo o governo federal, há cadastrados 219 Centros POP e 1.431 serviços de abordagem de rua ${ }^{19}$.

As redes de acolhimento temporário compõem um conjunto de Serviço Especializado em Abordagem Social, em especial para adolescentes e adultos, visando ao desenvolvimento de sociabilidades, na perspectiva de fortalecimento de vínculos interpessoais e/ou familiares que oportunizem a construção de novos projetos de vida. O problema é que a rede de acolhimento temporário não alcança por completo as necessidades das crianças, voltando-se mais para ações de acolhimento noturno, provendo dormitórios esporádicos. Tal proposta, além de não atender às necessidades de convivência familiar, provoca evasão.

O atendimento à infância tem como ponto norteador as ações propostas no Plano Nacional pela Primeira Infância (PNPI), criado em 2010 e alterado, em 2020, pela Lei n. ${ }^{\circ}$ 13.257/2016 (Lei de Políticas Públicas para a Primeira Infância), que, por sua vez, também altera o ECA. Tal plano visa garantir o atendimento dos direitos da criança de até seis anos, propondo metas para serem executadas em um período de até doze anos (2011 a 2022), com nova proposta abrangendo o período de 2020 a 2030, bem como elaboração de planos estaduais, distrital e municipais ${ }^{20}$.

Em 2017, o CONANDA, a Secretaria Nacional dos Direitos da Criança e do Adolescente (SNDCA/ $\mathrm{MDH}$ ) e a Campanha Nacional Criança "não é de Rua" lançaram o documento-guia "Diretrizes Nacionais para o Atendimento a Crianças e Adolescentes em Situação de Rua”. A publicação traz 64 diretrizes, que resultaram na Resolução n. ${ }^{\circ} 187$ do Conanda e nas conjuntas com o Conselho Nacional da Assistência Social (CNAS), Resoluções Conjuntas Conanda/CNAS n. ${ }^{\circ}$ 1/2016 e n. ${ }^{\circ}$ 1/2017 — um instrumento de orientação da rede de assistência social e demais políticas de atendimento à criança e ao adolescente em condição de vulnerabilidade trazida pela rua ${ }^{21}$.

\footnotetext{
19 BRASIL. Monitoramento CENTROPOP. 2017. Disponível em: <https://monitoramento.presidencia.gov.br/observatorio/web/ observatorio/crack/mapa/CentroPop>. Acesso em: 09 fev. 2017.

20 BRASIL. Plano Nacional Primeira Infância: 2010-2022 | 2020-2030. Rede Nacional Primeira Infância (RNPI); ANDI Comunicação e Direitos. $2^{a}$ ed. (revista e atualizada). Brasília, DF: RNPI/ANDI, 2020a. Disponível em https://andi.org.br/wp-content/uploads/2021/07/andi-plano-nacional-pela-primeira-infancia-pnpi-web.pdf. Acesso em: 21 de fevereiro de 2022.

${ }^{21}$ CONSELHO NACIONAL DE DIREITO DA CRIANÇA E DO ADOLESCENTE (CONANDA). Conanda Lança Diretrizes
} 
Posteriormente, o Decreto n. ${ }^{\circ}$ 9.894, de 27/07/201922, reestruturou o Comitê Intersetorial de Acompanhamento e Monitoramento da Política Nacional para a População em Situação de Rua, realocando-o como órgão consultivo do atual Ministério da Mulher, da Família e dos Direitos Humanos. O documento alterou seis artigos, do $9^{\circ}$ ao 14 , do Decreto n. ${ }^{0} 7.053$, de 23/12/2009, à Política Nacional para a População em Situação de Rua e seu Comitê Intersetorial de Acompanhamento e Monitoramento.

Atualmente, o reflexo do cenário pandêmico da Covid-19 aflora, ainda mais, a vulnerabilidade da população em situação de rua. As condições de vida dessas pessoas — sem acesso à alimentação adequada, higiene, limpeza, moradia segura e a sua permanência constante em locais públicos — levam à exposição ainda maior à contaminação e à gravidade de sequelas provocadas pela infecção do novo Coronavírus. Dessa forma, chamam atenção duas portarias importantes de articulação e estratégias para essa situação emergencial.

A primeira, Portaria n. ${ }^{\circ}$ 69, de 14/05/2020 ${ }^{23}$, da Secretaria de Assistência Social, traz, por intermédio da Nota Técnica n. ${ }^{\circ}$ 13/2020, recomendações gerais para a garantia de proteção social à população em situação de rua, inclusive imigrantes, no contexto da pandemia do novo Coronavírus, Covid-19. Considera a nota que as condições de vida dessas pessoas em situação de rua são ainda mais preocupantes pela exposição a riscos nos espaços públicos (sujeitas à violência, ao precário acesso à alimentação, à falta de locais adequados e seguros para dormir e fazer sua higiene pessoal, à falta de acesso a itens de higiene e limpeza e de condições para higienização de suas roupas, pertences, alimentos etc.) e pelas dificuldades de se manter o distanciamento social (a falta de moradia e o caráter coletivo dos serviços de acolhimento dificultam o distanciamento social).

Nela, observa-se o direcionamento para que as localidades elaborem Plano(s) de Contingência e Organização no âmbito do SUAS, com descrição de algumas medidas, entre elas, estão: orientações e informações sobre a pandemia e sobre serviços e locais de atendimento do SUAS; disponibilidade de itens básicos de subsistência; espaços e materiais para a realização de higiene pessoal (banheiros e chuveiros) e higienização de roupas; segurança de acolhida, por meio do acesso a Serviços de Acolhimento, moradia provisória, alojamento ou outras alternativas; inclusão no Cadastro Único e acesso a programas sociais e benefícios, a exemplo do Programa Bolsa Família, auxílio emergencial criado no contexto da pandemia e Benefício de Prestação Continuada (BPC); atenção especial àqueles que integrem grupos de risco, visando à sua proteção; atendimento e encaminhamentos à rede de saúde, inclusive nos casos de suspeita ou contaminação pelo novo Coronavírus.

A segunda, Portaria n..$^{\circ}$ 04, de 22/10/202024, do Ministério da Cidadania/Secretaria Especial do Desenvolvimento Social/Secretaria Nacional de Assistência Social, é direcionada mais especificamente para população em situação de rua usuária abusiva de substâncias psicoativas. Nesta, é aprovada a Nota Técnica n. ${ }^{\circ}$ 47/2020, com orientações e recomendações gerais para a atuação intersetorial e integrada entre a rede socioassistencial e as Comunidades Terapêuticas (CTs), requerendo atenção diferenciada e articulada do poder público, para execução de ações ágeis e estratégicas do Projeto «Acolhimento em Comunidades Terapêuticas de usuários de álcool e outras drogas que se encontram em situação de rua». A nota orienta a disponibilização de vagas para o acolhimento dessas pessoas e faz recomendações de ações intersetoriais e integradas entre os Centros de Referência de Assistência Social (CRAS), Centros de Referência Especializados de Assistência Social (CREAS), Centros de Referência para População em Situação de Rua (Centro Pop), equipes

Nacionais para o Atendimento a Crianças e Adolescentes em Situação de Rua. Disponível em: <https://www.direitosdacrianca.gov.br/noticias-2017/conanda-lanca-diretrizes-nacionais-para-o-atendimento-a-criancas-e-adolescentes-em-situacao-de-rua $>$. Acesso em: 08 out. 2019.

22 BRASIL. Decreto $n^{\circ}$ 9.894, de 27 de junho de 2019. Brasília, 2019.

23 BRASIL. Portaria conjunta n. ${ }^{\circ}$ 69, de 18 de maio de 2020, do Ministério da Cidadania/Secretaria Especial do Desenvolvimento Social/Secretaria Nacional de Assistência Social. Diário Oficial da União, edição 93 (seção 1, página 379), 2020 b.

24 BRASIL. Portaria Conjunta n. ${ }^{\circ}$ 04, de 22 de outubro de 2020, do Ministério da Cidadania/Secretaria Especial do Desenvolvimento Social/Secretaria Nacional de Assistência Social. Diário Oficial da União, edição 204 (seção 1, página 385), 2020c. 
de abordagem social, entre outros; e a Rede de Atenção Psicossocial (RAPS), composta pelas Comunidades Terapêuticas, Residências Terapêuticas, pelos Centros de Atenção Psicossocial (CAPS), entre outros.

Ainda sobre os dispositivos recentes, destaca-se a resolução n. ${ }^{\circ} 40$, de 13/10/2020 ${ }^{25}$, do Ministério da Mulher, da Família e dos Direitos Humanos/Conselho Nacional dos Direitos Humanos, a qual se "destina a estabelecer diretrizes para promoção, proteção e defesa dos direitos humanos das pessoas em situação de rua, crianças, adolescentes, adultas e idosas..." (art. $1^{\circ}$ ). Além das diretrizes gerais, o documento aborda a questão dos Direitos Humanos, especificando alguns direitos fundamentais, com peculiaridades para essa população, por exemplo: Direito à Cidade, Direito à Moradia; Assistência Social; Segurança Pública; Sistema de Justiça; Educação; Saúde; Direito das Mulheres; LGBTI; Trabalho; Segurança Alimentar e Nutricional; Cultura, Esporte e Lazer.

De qualquer modo, há preocupação com a normatização de políticas de atendimento emergencial para a população de rua. Há inquietação com o contágio e a transmissão do vírus diante da vulnerabilidade maior dessa população, mas a política de atendimento deve abranger, de forma geral, minimizando os efeitos da situação e contemplando, cada vez mais, direitos para essa população.

\subsection{Dimensão econômica}

A preocupação com a igualdade de renda, a fim de atenuar o efeito da pobreza e conseguir a emancipação e dignidade humana das pessoas em condição de exclusão econômica, fez surgir as políticas públicas econômicas compensatórias. Para Risatto, Martins e Almeidaa ${ }^{26}$, a concepção de políticas compensatórias é de que existe uma minoria em desvantagem, situada abaixo de uma "linha de pobreza", divisória utilizada para definir o público-alvo de tais políticas. A população de rua constitui a situação mais grave de desigualdade econômica e social.

A mais usual política compensatória se reflete nos programas de transferência de renda. No Brasil, eles se relacionam mais com a necessidade de enfrentamento emergencial da pobreza absoluta, que adquiriu destaque nas agendas públicas, do que propriamente com um programa que busca compensar os desajustes das mudanças do mundo do trabalho e das desigualdades reflexas da situação de nova pobreza ${ }^{27}$.

O Programa Bolsa Família (PBF) passou a ser um dos maiores instrumentos de política social em número de beneficiários no Brasil ${ }^{28}$. Criado pela Medida Provisória n. ${ }^{\circ}$ 132/2003 e instituído pela Lei n. ${ }^{\circ} 10.836$, em 09/01/2004, no governo de Luiz Inácio da Silva, unificou alguns programas de transferência direta de renda com condicionalidades, beneficiando famílias em situação de pobreza e de extrema pobreza ${ }^{29}$. O PBF atende a famílias inseridas no Cadastro Único para Programas Sociais do Governo Federal. O benefício varia com a composição e renda da família ${ }^{30}$.

\footnotetext{
25 BRASIL. Resolução n. ${ }^{\circ}$ 40, de 05 de novembro de 2020, do Ministério da Mulher, da Família e dos Direitos Humanos. Diário Oficial da União, edição 211 (seção 1, página 144), 2020d.

${ }_{26}$ RISSATO, Denise; MARTINS, Fernando José; ALMEIDA, Janaína Aparecida de Mattos. Políticas públicas compensatórias: uma discussão preliminar. Trabalho apresentado no $5^{\circ}$ Seminário Nacional Estado e Políticas Sociais. Unioeste, Cascavel, 2011.

27 CARNEIRO, Annova Míriam Ferreira. A centralidade da família no Programa Bolsa Família: análise referenciada no programa em São Luís - MA. Tese - Doutorado em Políticas Públicas. Universidade Federal do Maranhão, 2010.

28 RISSATO, Denise; MARTINS, Fernando José; ALMEIDA, Janaína Aparecida de Mattos. Políticas públicas compensatórias: uma discussão preliminar. Trabalho apresentado no $5^{\circ}$ Seminário Nacional Estado e Políticas Sociais. Unioeste, Cascavel, 2011.

29 O Programa Nacional de Renda Mínima vinculado à Educação - Bolsa-Escola (Lei 10.219, 11/04/2001) e o Programa Nacional de Acesso à Alimentação (PNAA) - Cartão Alimentação (Lei 10.689, 13/06/2003), transferência de renda não condicionada; o Programa Nacional de Renda Mínima vinculada à Saúde - Bolsa-Alimentação (MP 2.206-1, 06/09/2001), transferência de renda condicionada às ações da família em prol da educação e saúde; o Programa Auxílio-Gás (Decreto 4.102, 24/01/2002); e Cadastramento Único do Governo Federal (Decreto 3.877, 24/07/2001).

${ }^{30}$ BRASIL. Ministério da Cidadania - Secretaria Especial de Desenvolvimento Social. Bolsa Família repassa R\$2,6 bilhões de reais aos beneficiários em fevereiro, 2019a. Disponível em: <http://mds.gov.br/area-de-imprensa/noticias/2019/fevereiro/bolsa-familia-repassa-r-2-6-bilhoes-de-reais-aos-beneficiarios-em-fevereiro>. Acesso em: 11 set. 2019.
} 
Silva $^{31}$ aborda, como aspecto positivo do PBF, a ampliação do programa de transferência de renda para famílias sem filhos e moradores de rua, expondo que o PBF não foca, apenas, determinadas fases de vida e/ ou estados fisiológicos, e sim o combate à pobreza. A inserção de moradores de rua no PBF, no entanto, ainda é um desafio, devido à dificuldade de colocação dessa população no Cadastro Único de Programas Sociais, que oportunizam o ingresso em programas sociais promovidos pelo Governo Federal.

A política redistributiva do PBF foi um dos eixos do Plano Brasil sem Miséria (BSM), no governo Dilma Rousseff, preconizando a proteção à família inteira, ao invés do indivíduo, focalizado nas famílias vulneráveis. A proposta foi considerar todo o grupo familiar e, juntamente com os recursos financeiros para complementação da renda, estimular as famílias a frequentar e utilizar os serviços da rede pública de saúde, educação e assistência social ${ }^{32}$. O BSM, instituído pelo Decreto n. ${ }^{\circ}$ 7.492/11, de 02/06/2011, visou, por meio da articulação de políticas, programas e ações, à superação da situação de extrema pobreza da população brasileira. As alterações (Decreto n. ${ }^{\circ}$ 8.794/16) visaram: à elevação de renda familiar per capita dessa população; à ampliação do acesso aos serviços públicos; à geração de ocupações e renda por meio de ações de inclusão produtiva ${ }^{33}$.

Apesar dos benefícios, há discussão sobre a eficácia desses programas, cercada por vieses e polêmicas. De um lado, há a visão de que o PBF é uma política compensatória, baseada no assistencialismo. Para Druck e Figueiras ${ }^{34}$, o Bolsa Família constitui política assistencialista, clientelista e manipuladora do ponto de vista político, que pode ser reduzida e/ou retirada, ao sabor dos interesses de cada governo. De outro lado, há a visão de impacto positivo desses programas, que parte do pressuposto de que conceder crédito às familias implica ampliação do acesso ao consumo de bens e serviços, melhorando a capacidade das pessoas de fazer escolhas $^{35}$. Sobre o olhar favorável, Costa ${ }^{36}$ compreende que o Bolsa Família é uma política de transferência de renda condicionada ao cumprimento de contrapartidas comportamentais, o que significa a corresponsabilidade das famílias, especificamente nas áreas de saúde e educação.

Ainda na dimensão econômica, em 12/2006, o MDS lançou a Portaria 381, prevendo o cofinanciamento de serviços continuados de acolhimento institucional para população de rua, com municípios de mais de 250 mil habitantes. A portaria estabeleceu critérios/procedimentos para o repasse de recursos financeiros aos munícipios, destinados à expansão dos serviços socioassistenciais cofinanciados pelo Fundo Nacional de Assistência Social (FNAS), no âmbito do SUAS, ao desenvolvimento e aprimoramento da gestão dos Centros de Referência de Assistência Social (CRAS) e Centros de Referência Especializados de Assistência Social (CREAS), no exercício de 2006. Essa portaria impulsionou financeiramente a criação dos CREAS para Moradores de Rua (CREAS POP), já descritos na dimensão pessoa.

Em dezembro de 2010, o MDS, por meio da Portaria n. ${ }^{\circ} 843$, alterada pela Portaria n. ${ }^{\circ} 35$, de 23/04/2014, instituiu o cofinanciamento federal sobre o Piso Fixo de Média Complexidade (PFMC) dos serviços socioassistenciais ofertados pelos CREAS e Centros de Referência Especializados para População em Situação de Rua. Tais portarias fixaram os recursos repassados aos Estados e municípios para a criação e a manutenção dos serviços socioassistenciais de proteção social especial, incluindo os tratados para a população de rua.

\footnotetext{
31 SILVA, André Ricardo Fonsêca. Impacto do programa bolsa família na luta fundiária da comunidade quilombola da Caiana dos Crioulos: um estudo sobre cidadania. Tese - Programa de Pós-Graduação em Políticas Públicas e Formação Humana, da Universidade do Estado do Rio de Janeiro - UERFJ, Rio de Janeiro, 2015.

32 BRASIL. Lei Federal n. ${ }^{\circ}$ 10.836, de 09 de janeiro de 2004. Brasília, 2004.

33 CAMPELlO, Tereza; FALCÃO, Thiago; COSTA, Patricia Vieira. O Brasil Sem Miséria. Brasília: Ministério do Desenvolvimento Social e Combate à Fome, 2014.

34 DRUCK, Graça; FIGUEIRAS, Luiz. Política social focalizada e ajuste fiscal: as duas faces do governo Lula. Revista Katálysis, Florianópolis, v. 10, n. 1, p. 24-34, jan./jun. 2007 (Página 31).

35 DOMINGOS, Renata Martins. O direito à segurança de renda e o programa bolsa família: medidas de proteção e desproteção social no município de João Pessoa entre 2004 e 2014. Dissertação - Programa de pós-graduação em Ciências Jurídicas da Universidade Federal da Paraíba, João Pessoa, 2015.

36 COSTA, Rosita Soares Pereira. Bolsa família: Avaliação do impacto do programa sobre a pobreza no Brasil. Tese - Programa de Pós-Graduação em Economia da Universidade de Brasília - UnB, Brasília, 2015
} 
Cumpre ressaltar a importância das políticas macroeconômicas no combate à pobreza, as quais refletem no problema da situação de rua. Elas se constituem em um conjunto de medidas estatais que afetam o comportamento dos agregados econômicos, como renda, produto, nível geral de preços e emprego. Segundo Vasconcellos ${ }^{37}$, envolvem "a atuação do governo sobre a capacidade produtiva e despesas planejadas, com o objetivo de permitir que a economia opere a pleno emprego, com baixas taxas de inflação e com uma distribuição de renda justa". Esse foco não é dado nessa obra, mas não se pode deixar de refletir que uma das vertentes teóricas de explicação da "situação de rua", proposta por Ferreira ${ }^{38}$, relaciona-se a fatores "macro" - macrossociais e macroeconômicos —, como os processos de globalização econômica, urbanização acelerada e contexto dos movimentos sociais.

Segundo a "Pesquisa Nacional de Amostras por Domicílio Contínuo" ${ }^{39}$, cerca de 170 mil pessoas entraram no grupo de extrema pobreza do país (com menos de $\mathrm{R} \$ 1,90$ por dia). O Nordeste foi a única região com aumento da concentração de renda (Índice de Gini), com perda de renda para os 10\% mais baixos e renda alta para 1\% mais rico. Nesse contexto, a pandemia impõe desafios para essa parte mais pobre e, em especial, para uma parcela da população que se encontra em situação de vulnerabilidade.

A Portaria n. ${ }^{\circ}$ 369/2020 ${ }^{40}$, do Ministério da Cidadania, dispôs acerca do atendimento do Cadastro Único para Programas Sociais do Governo Federal no Distrito Federal e nos municípios que estejam em estado de calamidade pública, inclusive a Emergência de Saúde Pública de Importância Internacional declarada pela Organização Mundial da Saúde, em 30 de janeiro de 2020, em decorrência da infecção humana pelo novo Coronavírus (Covid-19). A partir dessa portaria, estabeleceram-se critérios e operacionalização, prevendo o repasse de recursos financeiros, visando à ampliação de capacidade de resposta do SUAS às demandas da população em situação de vulnerabilidade e risco social, ocasionada pela Covid-19.

Vale salientar que, de acordo com a PNAD-Contínua ${ }^{41}$, o Brasil, que hoje tem uma população estimada de 211.755.692 habitantes, teve uma taxa de desemprego equivalente a $14,6 \%$ no $3^{\circ}$ trimestre de 2020 , ou seja, 14,1 milhões de desempregados, aumentando 2,8 pp em relação ao mesmo período do ano anterior (as mulheres representavam 50,9\%). Como o IBGE também informa o percentual de pessoas afastadas do mercado de trabalho por desânimo, o número de desempregados pode não ter sido mais significativo, porque muitos pararam de procurar emprego em 2020, ou ficaram indisponíveis, devido à pandemia. Isso pode repercutir diretamente sobre os processos e programas de produtividade e inclusão no trabalho para a população em situação de rua neste momento.

Diante desse cenário, foi então instituído o Auxílio Emergencial, por meio da Lei n. ${ }^{\circ}$ 13.982/2020 $0^{42}$, regulamentada pelo Decreto n. ${ }^{\circ} 10.316 / 2020$, instituindo, entre outros aspectos, um benefício financeiro para trabalhadores individuais, microempreendedores individuais, autônomos e desempregados, para fornecer proteção emergencial durante o período de crise provocada pela Covid-19, em torno de $\mathrm{R} \$ 600,00$ mensais, pagos durante três meses.

Com desafios políticos e econômicos para continuidade do auxílio emergencial no ano de 2021 e face ao avanço da pandemia e ao aumento da pobreza, a situação tende a impor perdas mais significativas para a população mais vulnerável. Em recente reportagem, destacou-se que, no contexto de desigualdade e pobre-

\footnotetext{
37 VASCONCELLOS, Marcos Antônio Sandoval de. Fundamentos de Economia. São Paulo: Saraiva, 2005, p. 91.

38 PEREIRA, Felipe. Nas entranhas. Em São Paulo as pessoas já não moram somente embaixo, mas dentro de buracos de pontes e viadutos. Publicado em 19 de janeiro de 2021. Disponível em: https://tab.uol.com.br/edicao/pelas-entranhas/index.htm\#page2. Acesso em: 07/02/2021.

39 IBGE. Pesquisa Nacional por Amostra de Domicílios Contínua - PNAD Contínua trimestral. Disponível em: https://www.ibge.gov.br/ estatisticas/sociais/trabalho/17270-pnad-continua.html?=\&t=o-que-e. Acesso em: 05/02/2021.

40 BRASIL. Portaria n. ${ }^{\circ}$ 369, de 30 de abril de 2020, do Ministério da Cidadania. Diário Oficial da União, edição 82 (seção 1, página 17), 2020e.

41 IBGE. Pesquisa Nacional por Amostra de Domicílios Continua - PNAD Contínua trimestral. Disponível em: https://www.ibge.gov.br/

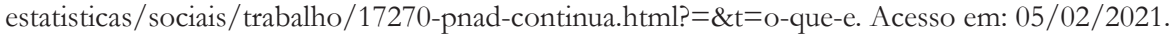

${ }^{42}$ BRASIL. Lei Federal n. ${ }^{\circ}$ 13.982, de 02 de abril de 2020. Brasília, 2020 f.
} 
za, mais pessoas estão em situação de rua no Brasil. Em São Paulo, as pessoas vivem sob viadutos e dentro de buracos em pontes e viadutos ${ }^{43}$.

A necessidade de isolamento social e de maior controle da higiene, com lavagem frequente das mãos e uso de álcool a 70\%, difundidos como mecanismos de controle do contágio da COVID - 19, desvelou, ainda mais, a desigualdade socioeconômica dessa população que já vem de um quadro de extrema vulnerabilidade, sendo desprovida das condições sanitárias mínimas. Muitos tinham como fonte geradora econômica a mendicância, as doações e os trabalhos informais prestados em feiras livres, comércios, praças e ruas. Os decretos com restrições diminuíram o movimento de pessoas que poderiam chegar mais próximos para ajudá-los e fecharam muitos lugares onde era possível desenvolver algumas atividades informais para obter seu sustento. As medidas rígidas de recolhimentos como a de lockdown, limitação de horário de permanência em lugares coletivos e suspensão de atividades em geral, ampliaram o desafio de sobrevivência para essa população. Di Lorenzo Lima, Carvalho \& Borges ${ }^{44}$ comentam sobre a contradição em se difundir o lema "fique em casa" enquanto essa população não tem sequer onde ficar, nem o que comer.

\subsection{Dimensão educacional}

A dimensão educacional agrega estratégias de políticas de superação da vulnerabilidade da criança ao processo educacional institucionalizado. A análise parte da capacidade de se criarem/recriarem métodos para a inserção dessa população na educação básica/profissionalizante.

O direito à educação é reconhecido na legislação. Além da CF de 1988 e do ECA, há lei que regulamenta o direito à educação, a Lei de Diretrizes e Bases da Educação (LDB), de 1996. O artigo 32, caput, da LDB reza que o ensino fundamental obrigatório, com duração de 9 (nove) anos, gratuito na escola pública, terá por objetivo a formação básica do cidadão.

Rizzini $^{45}$ afirma que a trajetória escolar de meninos e meninas de rua costuma ser irregular e confusa. Alguns tentam frequentar a escola, mas, durante o ano letivo, acabam desistindo. A escola — com horário predeterminado de chegada e de saída, com conteúdos programáticos longe da realidade da vivência na rua, além das experiências dos outros grupos escolares, geralmente com um grau mais acentuado de enquadramento social e familiar - constitui barreira na adaptação da população infanto-juvenil de rua.

Para Bandeira, Koller e Hutz ${ }^{46}$, a vivência da rua tem demonstrado outras formas de aprendizagem e desenvolvimento, adequadas a uma metodologia própria de ensino. Alguns programas e projetos de políticas públicas buscaram adequação das estruturas de escolarização na rua. Em 2014, ocorreu a expansão do Programa Nacional de Acesso ao Ensino Técnico e Emprego (Pronatec), com a criação do Pronatec Pop Rua, visando à qualificação profissional das pessoas em situação de rua e à sua inserção no mercado de trabalho ${ }^{47}$. O problema refere-se ao fato de que, em algumas cidades, houve obstáculos para a efetivação do programa no que se refere à empregabilidade, por falta de parceria dos empresários ${ }^{48}$.

\footnotetext{
43 PEREIRA, Felipe. Nas entranhas. Em São Paulo as pessoas já não moram somente embaixo, mas dentro de buracos de pontes e viadutos. Publicado em 19 de janeiro de 2021. Disponível em: https://tab.uol.com.br/edicao/pelas-entranhas/index.htm\#page2. Acesso em: 07/02/2021.

${ }^{44}$ Di LORENZO LiMA, W. C. G., CARVALHO, C. X. de, \& BORGES, M. C. de A. (2021). Situação de rua no referencial da sociedade de risco: o direito à liberdade e ao desenvolvimento. Revista Brasileira De Sociologia do Direito, 8(2), p. 212-238. https://doi. org/10.21910/rbsd.v8i2.376.

45 RIZZINI, Irene. Os Deserdados da Sociedade - Os 'Meninos de Rua' na América Latina. Rio de Janeiro: USU - Editora Universitária, 1995.

46 BANDEIRA, Denise Rushcel; KOLLER, Silva Helena; HUTZ, Cláudio Sinom. Desenvolvimento psicossocial e profissionalização: uma experiência com adolescentes de risco. Psicologia Reflexão e Crítica, Porto Alegre, v. 9, n. 1, p. 185-207, 1996.

47 BRASIL. Portaria SDH no 693, de 25 de novembro de 2014. Brasília, 2014. Disponível em: https://abmes.org.br/arquivos/legislacoes/Port-SDH-693-2014-11-25.pdf. Acesso em 04/04/2021.

48 CARTA CAPITAL. Em São Paulo, programa para moradores de rua enfrenta obstáculos, 2014. Disponível em: < https://www.cartacapital.com.br/sociedade/programa-para-profissionalizar-moradores-de-rua-em-sp-esbarra-na-empregabilidade-8441/> Acesso em:
} 
As propostas de inovação educacional para a população de rua são baseadas no modelo de educação fundamentado na Pedagogia Social, em que a educação é feita a partir de objetos e conhecimentos socialmente produzidos e de caráter interdisciplinar, articulando-se a outras áreas do conhecimento, como a Sociologia, Antropologia, Psicologia e História da Educação ${ }^{49}$.

Encontram-se na literatura relatos de tentativa de recriar a educação tradicional com inserção da educação social, em diferentes Estados brasileiros, fragmentados em propostas assistenciais, governamentais e não governamentais de educação e profissionalização de pessoas em situação de rua. Um exemplo é o Programa de Educação de Rua (PER), descrito por Rocha e Todesco ${ }^{50}$, quando levantaram a trajetória de proposta pedagógica com crianças e adolescentes nas ruas de São Paulo.

Visto isso, associa-se à dimensão educacional o guia de orientações técnicas para atuação no Centro de Referência Especializado para População em Situação de Rua (Centro POP). O documento-guia, publicado no dia 29/11/2011, tinha a finalidade educacional para construção de serviços de atendimento impulsionando a criação de guias estaduais e do Ministério Público para a defesa dos direitos das pessoas em situação de rua.

Segundo relatório da UNICEF (2021), com dados da Pnad sobre a situação educacional na pandemia, em outubro de 2020, foi registrado o percentual de 3,8\% (1.380.891) de crianças e adolescentes entre 6 e 17 anos que frequentavam a escola, seja no ensino presencial ou remoto. Conforme exposto, esse percentual foi superior ao apresentado em 2019 (2\%). Além disso, 11,2\% dos estudantes afirmaram estar na escola, confirmaram que não tiveram acesso às atividades escolares, contabilizando um total de aproximadamente 5,5 milhões de crianças e adolescentes sem adequado acesso à escola ou educação de qualidade.

Seja qual for o método educacional empregado, é notório que o distanciamento das crianças e adolescente em situação de extrema vulnerabilidade das escolas fica ainda mais evidente em tempo de pandemia. Com a suspensão das aulas presenciais, o isolamento social e o redirecionamento da educação para o ensino híbrido, a população infanto-juvenil em situação de rua enfrenta desafios para o alcance da educação formal ainda distantes de serem solucionados pela gestão escolar pública. Isto devido ao fato de que a nova conjuntura didática do ensino à distância que a pandemia exige recaí em problemas tecnológicos, de estrutura ambiental e social, que se entrelaçam em discussões mais amplas sobre a inclusão digital e inclusão escolar no país.

Desse modo, diversos fatores podem ser elencados para a distância dessa população à era atual da escola virtual, híbrida, ou mesmo das possibilidades que têm sido apontadas acerca do homeschooling. São fatos que demandam acesso a aparatos tecnológicos específicos (equipamentos, internet de última geração, entre outros), além de um ambiente doméstico adequado para atenção e concentração que se exige na assimilação dos conteúdos ofertados, mas que se sabe, não consiste na realidade de muitos que vivenciam as circunstâncias da situação de rua. Ainda, há o problema da alimentação, em muitos casos, referentes a merendas escolares que encontram os nutrientes enérgicos de sobrevivência.

Tudo isso se agrava devido às dificuldades de adaptação e de estrutura de funcionamento que o ensino à distância exige nesse tempo de pandemia, especialmente pelos problemas que a rede pública de ensino vem enfrentando. A UNESCO ${ }^{51}$, em relatório publicado em setembro de 2019, diz que a crise do Covid-19

10 out. 2019

49 CARVALHO, Josué de Oliveira; CARVALHO, Lindalva R. S. O. A educação social no Brasil: contribuições para o debate. Trabalho apresentado no I Congresso Internacional de Pedagogia Social. 2006. Disponível em: < http://www.proceedings.scielo.br/scielo.ph p?pid=MSC0000000092006000100024\&script=sci_arttext\&tlng=pt $>$ Acesso em: 24 abr. 2017.

50 ROCHA, Patrícia Rodrigues; TODESCO, Carla Alexandra do Amaral. Programa de educação de rua: Fundação Projeto Travessia. Trabalho apresentado no $1^{\circ}$ Congresso Internacional de Pedagogia Social, março 2006.

51 UNESCO. A Comissão Futuros da Educaşão da Unesco apela ao planejamento antecipado contra o aumento das desigualdades após a COVID-19. Paris: Unesco, 16 abr. 2020. Disponível em: https://pt.unesco.org/news/comissao-futuros-da-educacao-da-unesco-apela-aoplanejamento-antecipado-o-aumento-das. Acesso em: 4 jun. 2020. 
afetou mais de 90\% dos estudantes no mundo. Consagra a UNICEF ${ }^{52}$, em relatório sobre a acessibilidade do aprendizado remoto, o problema do número de crianças em locais em que o calendário das escolas e a manutenção das atividades de educação foram interrompidos devido à ocorrência da pandemia como uma emergência global, apresentando um número de 463 milhões de crianças em todo o mundo, desde a pré-escola até o ensino médio, sem continuidade nas suas atividades escolares. Segundo o relatório, pelo menos, $31 \%$ das crianças em idade escolar não foram alcançadas por programas de aprendizagem remota, sobretudo devido à falta de bens domésticos necessários ou de políticas focadas nas suas necessidades.

\subsection{Dimensão integridade física}

As pessoas que estão em situação de rua sofrem severas alterações no seu estado físico e no mental, dadas as precárias condições de alimentação, higiene, moradia, cuidados pessoais e exposição ao uso de drogas e álcool. A missão de aliviar o sofrimento humano e abraçar o bem-estar físico e mental, aparentemente vinculada ao acesso à saúde pública — ainda tão distante para essa população —, abrange políticas de aproximação à moradia digna, à alimentação saudável, de trabalho e de acesso à saúde pública.

A saúde das pessoas em situação de rua foi uma preocupação na instalação da Política Nacional para Inclusão Social da População de Rua. A Portaria n. 3.305 do Ministério da Saúde (MS), de 24/12/2009, instituiu o Comitê Técnico de Saúde da População em Situação de Rua, formado por representantes da sociedade civil, movimentos sociais e gestores do Ministério da Saúde. Dentre as atribuições do Comitê estabelecidas no artigo $2^{\circ}$, há ações de garantia do acesso, por essa população, aos serviços do SUS. O avanço foi dado pela Portaria n. ${ }^{\circ} 22$ do Ministério da Saúde, de 05/01/2011, criando o Programa Consultório de Rua.

O Ministério da Saúde, por meio da Secretaria de Atenção Básica à Saúde, lançou, em 2012, o Manual sobre Cuidado à Saúde juntamente à População em Situação de Rua, indicando diversas profissões para a composição dos Consultórios na Rua. Posteriormente, esse Ministério, por intermédio da Secretaria de Gestão Estratégica e Participativa (Seget-MS), aprovou, pela Resolução n. ${ }^{\circ} 2$ da Comissão Intergestores Tripartite do MS, de 27/02/2013, o plano operativo para implementação de ações em saúde para essa população. O plano definiu "diretrizes e estratégias de orientação para enfrentamento das iniquidades e desigualdades em saúde dessa população no âmbito do Sistema Único de Saúde”.

Para Macareta, Magalhães e Resende ${ }^{53}$, com a nova política de atendimento à saúde, a população de rua ganha espaço no SUS, com proposta de atendimentos na rua e em unidades fixas, envolvendo questões de saúde (ferimentos e enfermidades - tuberculose, hanseníase, HIV...), associadas a transtornos psicóticos graves e vulnerabilidades sociais extremas, uma realidade diferente de padrões estabelecidos.

Matraca, Araújo-Jorge e Wimmer ${ }^{54}$ ressaltam a participação do Agente Comunitário de Saúde de/na RUA como pilar da equipe. Isso porque o problema de saúde da população de rua não se concentra nas dificuldades de acesso ao modelo intervencionista de tratamento a patologias, mas também no alcance da saúde pública preventiva, no acompanhamento do desenvolvimento físico e mental da criança e do adolescente. Sem isso, eles crescem praticamente desprovidos da possibilidade de se construírem diagnósticos precoces.

\footnotetext{
52 UNICEF. Covid-19: are children able to continue learning during school closures? a global analysis of the potential reach of remote learning policies using data from 100 countries. https://www.unicef.org/brazil/media/10006/file/remote-learning-factsheet.pdf. Acesso em: 04/06/2021.

53 MACARETA, Iacã; MAGALHÃES, Juliana Neuenschwander; RESENDE, Noelle Coelho. In: GRINOVER, Ada Pellegrini et al. (Org.). Direitos fundamentais das pessoas em situação de rua. Belo Horizonte: Editora D’Plácito, 2014, p. 293.

${ }^{54}$ MATRACA, Marcus Vinicius Campos; ARAÚJO-JORGE, Tania Cremonini; WIMMER, Gert. O PalhaSUS e a Saúde em Movimento nas Ruas: relato de um encontro. Revista Interface - comunicação, saúde e educação, Botucatu (SP) ano 18, supl 2, p. 529-1536, 2014. Disponível em: <http://interface.org.br/edicoes/v-18-supl-2-2014>. Acesso em: 16 jun. 2017.
} 
Importa salientar que, com o objetivo de ampliar o escopo dessas ações, a Portaria n. ${ }^{\circ} 1.553$, de 01/07/2019 do Ministério da Saúde ${ }^{55}$, abriu espaço para que os municípios pudessem credenciar os programas para receberem incentivos financeiros, referentes às equipes de Consultório na Rua (eCR).

Falar em saúde também requer a discussão sobre as condições de moradia e de higiene, o direito à moradia digna é pressuposto para a dignidade humana, desde 1948, com a Declaração Universal dos Direitos Humanos e recepcionada pela CF de 1988, pela Emenda Constitucional n. ${ }^{\circ} 26 / 00$, em seu artigo $6^{\circ}$, caput.

Do ponto de vista de preocupação com a política de moradia, a Portaria n. ${ }^{\circ}$ 595, de 12/2013, do antigo Ministério das Cidades, definiu a população em situação de rua como alvo prioritário de programas de habitação, como o "Minha Casa Minha Vida" (PMCMV), que foi instituído em 2009, pela Lei n.o 11.977, para reduzir o déficit habitacional, ampliando subsídio para a faixa de pessoas com renda familiar até três salários-mínimos e adotando medidas para reduzir o custo da habitação (desoneração tributária para a habitação de interesse social, barateamento do seguro e criação do Fundo Garantidor da Habitação).

O PMCMV compreende dois subprogramas: Programa Nacional de Habitação Urbana (PNHU) e Programa Nacional de Habitação Rural (PNHR), com estrutura operacional em linhas por faixa de renda dos beneficiários. Na primeira faixa, está o grupo de renda familiar mensal mínima. A seleção é feita pelas prefeituras municipais ou Distrito Federal, pelos critérios da Lei Federal n. ${ }^{\circ}$ 11.977/2009. Essa Lei estabelece preferência para: (a) famílias residentes em áreas de risco, insalubres, desabrigadas; (b) famílias com mulheres responsáveis pela unidade familiar; e (c) famílias com pessoas portadoras de necessidades especiais ${ }^{56}$.

No PMCMV enquadram-se também as pessoas em situação de rua, mas é um desafio: muitos não têm renda, ou, quando têm, são inconstantes, não podendo se comprometer com contrapartidas financeiras; as cotas geralmente não são cumpridas pelas prefeituras, ou, quando são, não atendem à demanda; poucos são contemplados, porque a base da inserção é o sorteio; há um longo processo burocrático até a entrega da unidade habitacional. Além disso, as crianças e os adolescentes que se encontram em situação de rua não podem aderir, de forma pessoal, ao programa e constantemente estão na rua sem seus pais/responsáveis, restando, como políticas de atendimento, voltar para o babitat da família, ou serem inseridos em acolhimento institucional/familiar ${ }^{57}$.

É possível encontrar outras tentativas de políticas habitacionais para moradores de rua, como a locação social ou auxílio-moradia — benefício temporário, para remoção de familias domiciliadas em áreas de risco, desabrigadas por vulnerabilidade temporária ou calamidade pública. Trata-se de um recurso assistencial mensal, por tempo determinado, equivalente ao custo de um aluguel popular, em caráter de urgência. Como a responsabilidade do aluguel é da pessoa em situação de vulnerabilidade, há dificuldade em conseguir formalmente alugar uma residência, devido aos entraves burocráticos dos contratos de aluguéis e de preconceitos quanto à situação social. Além disso, ao alugar um imóvel, geralmente, com o valor estipulado de uma moradia popular, aquele não é acompanhado pelos móveis e utensílios, aumentando a dificuldade de estruturação do lar.

Além da habitação, a saúde física inclui a alimentação adequada, um direito contemplado no artigo 25 da Declaração Universal dos Direitos Humanos de 1948, no Pacto de Direitos Econômicos, Sociais e Culturais e no Comentário Geral n. 12 da ONU. Tal direito é contemplado nas políticas públicas de Segurança Alimentar e Nutricional (SAN), abraçadas pelo Programa Bolsa Família.

\footnotetext{
55 BRASIL. Portaria n. ${ }^{\circ}$ 1.553, de 04 de julho de 2019, do Ministério da Saúde. Diário Oficial da União, edição 127 (seção 1, página 84), 2019b.

56 MARQUES, Laura Marques de. Minha Casa Minha Vida: Análise da percepção de valor sobre as áreas comuns. Dissertação Programa de Pós-Graduação em Planejamento Urbano e Regional. Universidade Federal do Rio Grande do Sul, Porto Alegre, 2015. 57 MARQUES, Laura Marques de. Minha Casa Minba Vida: Análise da percepção de valor sobre as áreas comuns. Dissertação Programa de Pós-Graduação em Planejamento Urbano e Regional. Universidade Federal do Rio Grande do Sul, Porto Alegre, 2015.
} 
A segurança alimentar e nutricional, que adquiriu centralidade nas agendas governamentais dos últimos anos, com a Lei Orgânica de Segurança Alimentar (LOSAN), Lei Federal n. ${ }^{\circ}$ 11.346/2006, e com a EC 64, integrou, no art. $6^{\circ}$ da CF, o direito à alimentação $0^{58}$. A alimentação adequada passou a ser considerada um direito dos cidadãos e um dever do Estado, tornando obrigatórias medidas para redução da fome, priorizando as pessoas em situação de insegurança alimentar e nutricional ${ }^{59}$.

A Política Nacional para a População em Situação de Rua, descrita nos objetivos do art. $7^{\circ}$, vincula-se a "implementar ações de segurança alimentar e nutricional suficientes para proporcionar acesso permanente à alimentação pela população em situação de rua à alimentação, com qualidade" ${ }^{60}$. A alimentação das crianças e dos adolescentes em situação de rua geralmente associa-se à mendicância e a trabalhos informais. É comum a busca de alimentos em sobras de restaurantes e feiras, por ações filantrópicas e programas sociais de distribuição de alimentos, a exemplo dos sopões. Entende-se que o direito à alimentação somente alcança uma verdadeira dimensão humana quando contempla as necessidades funcionais e a garantia da saúde integral $^{6162}$.

Sobre a dimensão bem-estar físico e mental, há, na falta de acesso ao mercado de trabalho, uma característica das pessoas em situação de rua. Com o foco na infância e juventude, o problema é o acesso precoce ao mundo de trabalho irregular. A exploração da mão de obra infantil, a hipervulnerabilidade para trabalho degradante e impactos para o desenvolvimento pessoal são preocupações das políticas públicas para infância e juventude.

No Brasil, a CF de 1988 dispõe, no art. 7º XXXIII, alterado pela EC n. ${ }^{\circ}$ 20, de 1998, a proibição "de trabalhos noturno, perigoso ou insalubre a menores de dezoito anos e de qualquer trabalho a menores de dezesseis anos, salvo na condição de aprendiz, a partir de quatorze anos”. Em consonância, a Consolidação das Leis do Trabalho (CLT) readequou a redação do art. 403, dispondo que é proibido qualquer trabalho a menores de dezesseis anos de idade, salvo na condição de aprendiz, a partir dos 14 anos. Destaca-se, ainda, que o Decreto n. ${ }^{\circ} 3.597$, de 12/09/2000, da Presidência da República, promulga a Convenção 182 e a Recomendação 190 da Organização Internacional do Trabalho (OIT) sobre a Proibição das Piores Formas de Trabalho Infantil e a Ação Imediata para a sua eliminação.

Sobre a integridade física, é importante destacar as normativas publicadas em caráter excepcional para o enfrentamento pandêmico. Nela, há a Portaria de n. ${ }^{\circ} 54$, publicada em $1^{\circ}$ de abril de 2020, pelo Ministério da Cidadania / Secretaria Especial do Desenvolvimento Social / Secretaria Nacional de Assistência Social, a qual aprova, por meio de nota técnica, recomendações gerais aos gestores e trabalhadores do Sistema Único de Assistência Social (SUAS) dos Estados, Municípios e do Distrito Federal, com o objetivo de garantir a continuidade da oferta de serviços e atividades essenciais da Assistência Social, com medidas e condições que garantam a segurança e a saúde dos usuários e profissionais do SUAS.

Particularmente o documento trouxe recomendações gerais para o funcionamento do Centro de Referência Especializado para População em Situação de Rua (CENTRO POP), durante a situação de emergência em saúde pública, as quais englobam, entre outros: equipamentos abertos e suspensão temporária de atividades coletivas; medidas para evitar aglomeração, a exemplo de atendimento presencial com distanciamento de pelo menos um metro entre as pessoas; utilização de ambientes amplos, arejados e limpos, podendo ser, inclusive, locais abertos, como varandas, quintais e tendas, observadas as condições de privacidade;

\footnotetext{
58 BRASIL. Lei Federal n. ${ }^{\circ} 11.346$, de 15 de setembro de 2006. Brasília, 2006.

59 MÜLLER, Marcela. O direito social fundamental à alimentação adequada e sua proteção no contexto das organizaçães internacionais. 2014. Dissertação - Programa de Pós-Graduação em Direito, Programa de Pós-Graduação em Direito da Faculdade de Direito da Universidade de Itaúna. Itaúna, 2014.

${ }^{60}$ BRASIL. Decreto Lei $n^{\circ}$ 7.053, de 23 de dezembro de 2009. Brasília, 2009.

${ }^{61}$ COMPARATO, Fábio Konder. A Afirmação bistórica dos Direitos Humanos. 10. ed. São Paulo: Saraiva, 2015.

62 VAZ, José Eduardo Parlato Fonseca. O Direito Social à Alimentação. Associação Brasileira de Direito Processual. 2010. Disponível em: <http://www.tex.pro.br/home/artigos/37-artigos-ago-2010/3661-o-direito-social-a-alimentacao> Acesso em: 15 jun. 2017.
} 
acesso à alimentação, aos espaços para higiene pessoal e a kits de higiene, de forma organizada, evitando aglomerações; limpeza sistemática do ambiente e a observância de recomendações sanitárias locais quanto à guarda de pertences individuais, considerando o tempo de sobrevida do vírus em objetos; encaminhamentos para serviços de acolhimento ou para outras alternativas de acolhimento a esta população, além de atendimentos às demandas de saúde; ações das equipes de abordagem social com uso de carro de som, megafones e outros meios, para facilitar o trabalho nos espaços públicos.

\subsection{Dimensão sociofamiliar}

O delineamento da dimensão sociofamiliar abarca as ações de reintegração familiar de crianças e adolescentes em situação de rua, no processo de retorno às suas famílias de origem (natural ou extensa), após terem passado por acolhimento institucional, familiar ou somente pela rua. Abrange também a criação de novos laços em famílias substitutas, constituídas por múltiplos arranjos familiares.

As políticas fundadas nas orientações do ECA devem objetivar a preservação de vínculos familiares e comunitários, opondo-se à institucionalização de crianças e adolescentes, o que contribui para o afastamento familiar e comunitário. O Plano Nacional de Promoção, Proteção e Defesa do Direito de Crianças e Adolescentes à Convivência Familiar e Comunitária, publicado em 2006, pelo MDS, foi um importante documento que reflete a responsabilidade das políticas sociais, em especial, o atendimento às famílias em situação de maior vulnerabilidade social e pessoal. Entre as suas diretrizes, existe a responsabilidade do Estado nas políticas integradas de apoio à família.

Seron ${ }^{63}$ argumenta que o rompimento fortuito com a família natural, estabelecendo a destituição do poder familiar, somente pode ocorrer em último caso, quando for constatado que existe, de fato, algo maior que impeça a permanência da criança e do adolescente na família de origem. Para Suziani Lemos ${ }^{64}$, uma das tarefas mais desafiadoras e difíceis para os profissionais do Direito reside nas demandas do Poder Judiciário as quais envolvam pedido de suspensão ou destituição do poder familiar. A dificuldade está em identificar o melhor para a criança, diante da complexidade do conflito.

Entre os objetivos do Plano Nacional de Promoção, Proteção e Defesa do Direito de Crianças e Adolescentes à Convivência Familiar e Comunitária (PNCFC), está "a necessidade de articulação e integração das políticas, programas, projetos, serviços e ações de apoio sociofamiliar" ${ }^{65}$. Parte-se da integralidade da rede psicossocial de proteção como paradigma de busca das potencialidades da família, protagonista da situação de rua, com inúmeros fatores sociais e econômicos que levam à vulnerabilidade.

O CONANDA e o CNAS, por meio da Resolução Conjunta com outros órgãos, publicaram o CNAS/ CONANDA n. ${ }^{\circ}$ 1, de 18 de junho de 2009, com as Orientações Técnicas para os Serviços de Acolhimento para Crianças e Adolescentes, regulamentando a organização e a oferta de serviços de acolhimento. Em 2013, houve o processo de expansão e reordenamento desses serviços para crianças, adolescentes e jovens até 21 anos, com a publicação das Resoluções n. ${ }^{\circ} 15$ e 17, pela Comissão Intergestores Tripartite (CIT) e da aprovação das Resoluções n. ${ }^{\circ} 23$ e 31, pelo Conselho Nacional de Assistência Social (CNAS).

Pela Resolução Conjunta CNAS/CONANDA n. ${ }^{\circ} 1$ (15/12/2016), o documento “Orientações Técnicas: Serviços de Acolhimento para Crianças e Adolescentes" foi modificado, sendo incluído o subitem 4.6, no

\footnotetext{
${ }_{63}$ SERON, Paulo César. Destituição do poder e drogadição: a psicologia e as intervenções familiares. In: Congresso Internacional da Psicologia da UEM: Psicologia e direitos humanos: formação, atuação e compromisso social, VI, 2015, Maringá - PR. Anais... Maringá, 2015. Disponível em: <http://cipsi.vwi.co.br/anais/publicacoes/letter/d>. Acesso em: 06 abr. 2017.

${ }^{64}$ LEMOS, Suziani de Cássia Almeida. A família e a destituição do poder familiar - um estudo psicanalítico. Dissertação - Programa de Pós-Graduação em Psicologia, Universidade Federal de Uberlândia, Uberlândia - MG, 2015.

65 BRASIL. Plano Nacional de Promoção, Proteção e Defesa do Direito de Crianças e Adolescentes à Convivência Familiar e Comunitária (PNCFC). 2006. Disponível em: <https://www.mds.gov.br/webarquivos/publicacao/assistencia_social/Cadernos/Plano_Defesa_CriancasAdolescentes\%20.pdf>. Acesso em: 10 out. 2019.
} 
Capítulo III. Nele, crianças e adolescentes em situação de rua compõem um público que requer serviços diferenciados de atendimento e níveis de cuidado peculiar.

Os serviços de proteção social atuam por meio dos CRAS, com famílias e indivíduos em seu contexto comunitário, objetivando fortalecer os vínculos familiares e o convívio sociofamiliar e comunitário. Os de alta complexidade são aqueles que garantem proteção integral, moradia, alimentação, higienização e trabalho protegido para famílias e indivíduos que se encontram sem referência e, ou, em situação de ameaça, necessitando ser retirados de seu núcleo familiar/comunitário. A ponderação entre a necessidade e a possibilidade de reintegração familiar deve ser tratada nas políticas de atendimento sem perder de vista que o direito à convivência familiar não pode se limitar à família natural, sendo esta prioridade, mas não a única probabilidade.

Essa visão foi fortalecida ainda mais com a publicação da Recomendação Conjunta n. ${ }^{\circ}$, publicada em 16 de abril de 2020, pelo Conselho Nacional de Justiça, Conselho Nacional do Ministério Público, Ministério do Estado da Cidadania, Ministério do Estado da Mulher, da Família e dos Direitos Humanos ${ }^{66}$. Tais recomendações levantam a possibilidade de medidas e procedimentos emergenciais que assegurem a continuidade da oferta dos serviços de acolhimento, a prevenção da transmissibilidade do novo Coronavírus, Covid-19, e a proteção de crianças, adolescentes e profissionais do Sistema Único de Assistência Social - SUAS.

Entre as medidas e procedimentos, estão: a priorização de procedimentos para concessão de guarda provisória a pretendentes previamente habilitados para adoção de crianças e adolescentes em serviços de acolhimento, que estão em estágio de convivência para adoção; reintegração familiar de crianças e adolescentes em serviços de acolhimento institucional, quando observadas as condições seguras para cuidado e proteção juntamente à família de origem, nuclear ou extensa; funcionamento emergencial com cuidado do fluxo diário de entrada e saída de profissionais, adaptação do espaço físico, reorganização dos serviços nas instituições de acolhimento e atendimento em subgrupos de até dez crianças e/ou adolescentes; sensibilização das Famílias Acolhedoras habilitadas, para que possam acolher mais de uma criança ou adolescente. Além do mais, reforça a figura do padrinho afetivo e levanta a chance, em caráter excepcional, depois de esgotadas as possibilidades de manutenção da medida de acolhimento institucional, da permanência da criança ou adolescente, por decisão judicial, na residência de cuidadores diretos, de demais profissionais do serviço de acolhimento ou de padrinhos afetivos ${ }^{67}$.

Todas as recomendações contidas no documento visam assegurar condições adequadas das instituições de acolhimento para o enfrentamento do contágio do Covid, bem como buscar meios alternativos para diminuir o fluxo de crianças e adolescentes nas instituições, retirando-as de qualquer possibilidade de aglomeração.

\section{Considerações finais}

Os poucos registros das efetivas ações governamentais federais traçadas diretamente para a infância e juventude em situação de rua necessitaram aqui integrar conceitos e dimensionar critérios, para entender melhor a evolução das diretrizes e do conjunto normativo das escolhas governamentais de políticas públicas destinadas a essa população-alvo.

\footnotetext{
${ }_{66}$ BRASIL. Recomendação Conjunta n. ${ }^{\circ}$, de 17 de abril de 2020, do Conselho Nacional de Justiça, Conselho Nacional do Ministério Público, Ministério da Cidadania, Ministério da Mulher, da Família e dos Direitos Humanos. Diário Oficial da União, edição 74-A (seção 1 - extra, página 1), 2020g.

${ }^{67}$ BRASIL. Recomendação Conjunta n. ${ }^{\circ}$ 1, de 17 de abril de 2020, do Conselho Nacional de Justiça, Conselho Nacional do Ministério Público, Ministério da Cidadania, Ministério da Mulher, da Família e dos Direitos Humanos. Diário Oficial da União, edição 74-A (seção 1 - extra, página 1), 2020g.
} 
Observou-se que existe, sim, um sistema normativo norteador, base para implantação de políticas públicas que visem à reintegração familiar e social de crianças e adolescentes em situação de rua. Houve um redirecionamento das diretrizes dessas políticas nos últimos anos, dadas como passo inicial em 2009 e ampliadas agora com a situação e as demandas que envolvem o cenário da pandemia do novo Coronavírus. $\mathrm{O}$ foco de mudanças foi a criação de políticas para um sistema de amparo pessoal e familiar, em substituição às antigas políticas de institucionalização de menores nas ruas.

As dimensões didaticamente escolhidas para investigação histórica normativa não podem ser vistas de forma isolada, devem ser interligadas aos direitos fundamentais que estão sendo violados na condição de rua.

A questão ainda está longe de ser superada, as diretrizes normativas não nos asseguram a implantação e a obrigação de execução de tais políticas. Descobre-se, portanto, que a legislação vigente é ineficiente no sentido de cobrar a responsabilização dos Estados e municípios, pelo cumprimento das diretrizes normativas federais dos direitos da criança e do adolescente em situação de rua. Há necessidade de mecanismos jurídicos mais contundentes de cobrança para a responsabilização dos gestores públicos. Necessita-se, contudo, mais ainda, que a população entenda que o problema envolve todos: sociedade, família e Estado.

\section{Referências}

aBRAMOVICH, Victor. Linhas de trabalho em direitos econômicos, sociais e culturais: instrumentos e aliados. Revista Internacional de direitos bumanos - SUR, ano 2, n. 2, p. 188-223, 2005.

BANDEIRA, Denise Rushcel; KOLLER, Silva Helena; HUTZ, Cláudio Sinom. Desenvolvimento psicossocial e profissionalização: uma experiência com adolescentes de risco. Psicologia Reflexão e Crítica, Porto Alegre, v. 9, n. 1, p. 185-207, 1996.

BRASIL. Ações da Política Nacional. Ministério da Mulher, da Família e dos Direitos Humanos, 2014. Disponível em: <https://www.mdh.gov.br/navegue-por-temas/populacao-em-situacao-de-rua/acoes-da-politica-nacional>. Acesso em: 10 out. 2019.

. Decreto Lei $n^{\circ}$ 7.053, de 23 de dezembro de 2009. Brasília, 2009.

. Guia de politicas públicas de juventude. Brasília: Secretaria Geral da Presidência da República, 2006.

Disponível em: <http://bibjuventude.ibict.br/jspui/bitstream/192/117/1/guiajuventude1.pdf> Acesso em: 06 jul. 2014.

. Lei Federal n. ${ }^{\circ}$ 8.069, de 13 de julho de 1990. Brasília, 1990a.

Lei Federal n. ${ }^{\circ}$ 8.080, de 19 de setembro de 1990. Brasília, 1990b.

Lei Federal n. ${ }^{\circ}$ 11.258, de 30 de dezembro de 2005. Brasília, 2005.

. Lei Federal n. 13.146, de 06 de julho de 2015. Brasília, 2015.

Lei Federal n. ${ }^{\circ}$ 13.257, de 08 de março de 2016. Brasília, 2016a.

. Lei Federal n. ${ }^{\circ}$ 12.852, de 05 de agosto de 2013. Brasília, 2013a.

. Lei Federal n. ${ }^{\circ}$ 12.696. de 25 de julho de 2012. Brasília, 2012.

. Lei Federal n. ${ }^{\circ}$ 10.836, de 09 de janeiro de 2004. Brasília, 2004.

Lei Federal n. ${ }^{\circ}$ 13.982, de 02 de abril de 2020. Brasília, 2020f.

. Ministério da Cidadania - Secretaria Especial de Desenvolvimento Social. Bolsa Família repassa

$R \$ 2,6$ bilhões de reais aos beneficiários em fevereiro, 2019a. Disponível em: <http://mds.gov.br/area-de-impren- 
sa/noticias/2019/fevereiro/bolsa-familia-repassa-r-2-6-bilhoes-de-reais-aos-beneficiarios-em-fevereiro> Acesso em: 11 set. 2019.

. Monitoramento CENTROPOP. 2017. Disponível em: < https://monitoramento.presidencia.gov.br/ observatorio/web/observatorio/crack/mapa/CentroPop>. Acesso em: 09 fev. 2017.

- Plano Nacional de Promoção, Proteção e Defesa do Direito de Crianças e Adolescentes à Convivencia Familiar e Comunitária (PNCFC). 2006. Disponível em: < https://www.mds.gov.br/webarquivos/publicacao/assistencia_social/Cadernos/Plano_Defesa_CriancasAdolescentes\%20.pdf>. Acesso em: 10 out. 2019.

. Plano Nacional Primeira Infância: 2010-2022 | 2020-2030. Rede Nacional Primeira Infância (RNPI); ANDI Comunicação e Direitos. $2^{a}$ ed. (revista e atualizada). Brasília, DF: RNPI/ANDI, 2020a. Disponível em https://andi.org.br/wp-content/uploads/2021/07/andi-plano-nacional-pela-primeira-infancia-pnpi-web.pdf. Acesso em: 21 de fevereiro de 2022.

. Política Nacional para inclusão social da População em situação de rua. 2008b. Disponível em: <http:// www.recife.pe.gov.br/noticias/arquivos/2297.pdf> Acesso em: 25 set. 2016.

Portaria conjunta n. ${ }^{\circ}$ 69, de 18 de maio de 2020, do Ministério da Cidadania/Secretaria Especial do Desenvolvimento Social/Secretaria Nacional de Assistência Social. Diário Oficial da União, edição 93 (seção 1, página 379), 2020b.

. Portaria Conjunta n. ${ }^{\circ}$ 04, de 22 de outubro de 2020, do Ministério da Cidadania/Secretaria Especial do Desenvolvimento Social/Secretaria Nacional de Assistência Social. Diário Oficial da União, edição 204 (seção 1, página 385), 2020c.

. Portaria da SDH n. ${ }^{\circ}$ 693, de 25 de novembro de 2014. Brasília, 2014. Disponível em: https://abmes.org.br/arquivos/legislacoes/Port-SDH-693-2014-11-25.pdf. Acesso em 04/04/2021.

. Portaria n. ${ }^{\circ}$ 369, de 30 de abril de 2020, do Ministério da Cidadania. Diário Oficial da União, edição 82 (seção 1, página 17), 2020e.

. Portaria n. ${ }^{\circ}$ 1.553, de 04 de julho de 2019, do Ministério da Saúde. Diário Oficial da União, edição 127 (seção 1, página 84), 2019b.

. Recomendação Conjunta n..$^{\circ}$, de 17 de abril de 2020, do Conselho Nacional de Justiça, Conselho Nacional do Ministério Público, Ministério da Cidadania, Ministério da Mulher, da Família e dos Direitos Humanos. Diário Oficial da União, edição 74-A (seção 1 - extra, página 1), 2020g.

Resolução n. ${ }^{\circ}$ 40, de 05 de novembro de 2020, do Ministério da Mulher, da Família e dos Direitos Humanos. Diário Oficial da União, edição 211 (seção 1, página 144), 2020d.

CAMPELlO, Tereza; FALCÃO, Thiago; COSTA, Patricia Vieira. O Brasil Sem Miséria. Brasília: Ministério do Desenvolvimento Social e Combate à Fome, 2014. Disponível em: <https://www.mds.gov.br/webarquivos/publicacao/brasil_sem_miseria/livro_o_brasil_sem_miseria/livro_obrasilsemmiseria.pdf.> Acesso em: 21 ago. 2017.

CANELA JÚNIOR, Osvaldo. A efetivação dos direitos fundamentais através do direito coletivo: o âmbito de cognição das políticas públicas pelo poder judiciário. Tese - Programa de pós-graduação em Direito, Universidade de São Paulo, 2009.

CARNEIRO, Annova Míriam Ferreira. A centralidade da família no Programa Bolsa Família: análise referenciada no programa em São Luís - MA. 2010. Tese - Doutorado em Políticas Públicas. Universidade Federal do Maranhão, 2010.

CARTA CAPITAL. Em São Paulo, programa para moradores de rua enfrenta obstáculos, 2014. Disponível em: $<$ https://www.cartacapital.com.br/sociedade/programa-para-profissionalizar-moradores-de-rua-em-sp-esbarra-na-empregabilidade-8441/> Acesso em: 10 out. 2019. 
CARVALHO, Josué de Oliveira; CARVALHO, Lindalva R. S. O. A educaşão social no Brasil: contribuições para o debate. Trabalho apresentado no I Congresso Internacional de Pedagogia Social. 2006. Disponível em: <http://www.proceedings.scielo.br/scielo.php?pid=MSC0000000092006000100024\&script=sci_ arttext\&tlng=pt> Acesso em: 24 abr. 2017.

COMPARATO, Fábio Konder. A afirmação histórica dos Direitos Humanos. 10. ed. São Paulo: Saraiva, 2015.

CONSELHO NACIONAL DO MINISTÉRIO PÚBLICO. Guia de Atuação Ministerial: defesa dos direitos das pessoas em situação de rua. Brasília: CNMP, 2015.

CONSELHO NACIONAL DE DIREITO DA CRIANÇA E DO ADOLESCENTE (CONANDA). Conanda lança Diretrizes Nacionais para o Atendimento a Crianças e Adolescentes em Situação de Rua. Disponível em: $<$ https://www.direitosdacrianca.gov.br/noticias-2017/ conanda-lanca-diretrizes-nacionais-para-o-atendimento-a-criancas-e-adolescentes-em-situacao-de-rua> . Acesso em: 08 out. 2019.

COSTA, Rosita Soares Pereira. Bolsa família: Avaliação do impacto do programa sobre a pobreza no Brasil. Tese - Programa de Pós-Graduação em Economia da Universidade de Brasília - UnB, Brasília, 2015.

DOMINGOS, Renata Martins. O direito à segurança de renda e o programa bolsa família: medidas de proteção e desproteção social no município de João Pessoa entre 2004 e 2014. Dissertação - Programa de pós-graduação em Ciências Jurídicas da Universidade Federal da Paraíba, João Pessoa, 2015.

DRUCK, Graça; FIGUEIRAS, Luiz. Política social focalizada e ajuste fiscal: as duas faces do governo Lula. Revista Katálysis, Florianópolis, v. 10, n. 1, p. 24-34, jan./jun. 2007.

DI LORENZO LIMA, Wania. Cláudia Gomes, CARVALHO, Cynthia Xavier de, \& BORGES, Maria C. de Araújo. Situação de rua no referencial da sociedade de risco: o direito à liberdade e ao desenvolvimento. Revista Brasileira De Sociologia do Direito, 8(2), p. 212-238. https://doi.org/10.21910/rbsd.v8i2.376. 2021.

FERREIRA, Frederico Poley Martins. Crianças e adolescentes em situação de rua e seus macro determinantes. Revista Saúde e Sociedade, São Paulo, v. 20, n. 2, p. 338-349, 2011. Disponível em: <www.scielo.br/pdf/ sausoc/v20n2/07.pdf>. Acesso em: 20 abr. 2017.

FONSECA, Franciele Fagundes et al. As vulnerabilidades na infância e adolescência e as políticas públicas brasileiras de intervenção. Revista Paul Pediatria, v. 31, n. 2, p. 258-64, 2013. Disponível em: <www.scielo.br/ pdf/rpp/v31n2/19.pdf>. Acesso em: 18 jul. 2016.

IBGE. Pesquisa Nacional por Amostra de Domicílios Continua - PNAD Contínua trimestral. Disponível em: https://www.ibge.gov.br/estatisticas/sociais/trabalho/17270-pnad-continua.html? $=\& t={ }_{O}$-que-e. Acesso em: 05/02/2021.

LEAL, Mônica Clarissa Henning. A dignidade humana e o princípio da proporcionalidade como fundamentos e como parâmetro para o controle jurisdicional de políticas públicas. In: ALEXY, Robert; BAEZ, Narcisio Leandro Xavier; SILVA, Rogério Luiz Nery. Dignidade Humana, direitos sociais e não-positivismos incluso. Florianópolis: Qualis, 2015.

LEMOS, Suziani de Cássia Almeida. A família e a destituição do poder familiar - um estudo psicanalítico. Dissertação - Programa de Pós-Graduação em Psicologia, Universidade Federal de Uberlândia, Uberlândia - MG, 2015.

LIMA, Wânia C. G. Di Lorenzo. Crianças e adolescentes em situação de rua: propostas pedagógicas como instrumento de materialização do direito ao desenvolvimento. In: BORGES, Maria C. Araújo; SANCHES, Samyra H. Dal Farra Naspolini. Direito, Educação, Ensino e Metodologia Jurídicos I (Recurso eletrônico on-line). Florianópolis: CONPEDI, 2014. Disponível em: http://publicadireito.com.br/ artigos/?cod=a3e8b5e0becdbfb1. Acesso em: 20 jul. 2015. 
LIMA, Wânia C. Gomes Di Lorenzo. Meninos(as) da rua ou meninos(as) do estado: um estudo sobre a postura intervencionista estatal no enfrentamento da situação de rua. Tese - Programa de Pós-Graduação em Ciências Jurídicas. Universidade Federal da Paraíba, João Pessoa, 2017.

MACARETA, Iacã; MAGALHÃES, Juliana Neuenschwander; RESENDE, Noelle Coelho. In: GRINOVER, Ada Pellegrini et al. (Org.). Direitos fundamentais das pessoas em situação de rua. Belo Horizonte: Editora D’Plácito, 2014.

MARQUES, Laura Marques de. Minha Casa Minha Vida: Análise da percepção de valor sobre as áreas comuns. Dissertação - Programa de Pós-Graduação em Planejamento Urbano e Regional. Universidade Federal do Rio Grande do Sul, Porto Alegre, 2015.

MATRACA, Marcus Vinicius Campos; ARAÚJO-JORGE, Tania Cremonini; WIMMER, Gert. O PalhaSUS e a Saúde em Movimento nas Ruas: relato de um encontro. Revista Interface - comunicação, saúde e educação, Botucatu (SP) ano 18, supl 2, p. 529-1536, 2014. Disponível em: <http://interface.org.br/edicoes/v-18supl-2-2014>. Acesso em: 16 jun. 2017.

MÜLLER, Marcela. O direito social fundamental à alimentação adequada e sua proteção no contexto das organizações internacionais. 2014. Dissertação - Programa de Pós-Graduação em Direito, Programa de Pós-Graduação em Direito da Faculdade de Direito da Universidade de Itaúna. Itaúna, 2014.

PEREIRA, Felipe. Nas entranhas. Em São Paulo as pessoas já não moram somente embaixo, mas dentro de buracos de pontes e viadutos. Publicado em 19 de janeiro de 2021. Disponível em: https://tab.uol.com.br/ edicao/pelas-entranhas/index.htm\#page2. Acesso em: 07/02/2021.

PETRI, Maria José Constantino. O direito das crianças e adolescentes à convivência familiar e comunitária: responsabilidade da família, da comunidade e do estado. Tese - Programa de Pós-Graduação em Direito da Universidade de São Paulo, São Paulo, 2008.

POUSA JÚNIOR, Efren Fernandez. População em situação de rua: perspectivas atuais no resgate da cidadania e reinserção social. Dissertação - Programa de Pós-Graduação em Direito Político e Econômico, Universidade Presbiteriana Mackenzie, São Paulo, 2012.

RISSATO, Denise; MARTINS, Fernando José; ALMEIDA, Janaína Aparecida de Mattos. Políticas públicas compensatórias: uma discussão preliminar. Trabalho apresentado no $5^{\circ}$ Seminário Nacional Estado e Políticas Sociais. Unioeste, Cascavel, 2011. Disponível em: <http://cacphp.unioeste.br/projetos/gpps/midia/seminario6/arqs/Resumo_politicas_seguridade/Resumo_politicas_publicas_compensatorias_discussao_preliminar.pdf>. Acesso em: 15 abr. 2017.

RIZZINI, Irene; NOIFFE, Luciana; BAPTISTA, Rachel. Experiência de promoção do direito à convivência familiar e comunitária no Brasil. São Paulo: Cortez, 2006.

RIZZINI, Irene. Os Deserdados da Sociedade - Os 'Meninos de Rua' na América Latina. Rio de Janeiro: USU - Editora Universitária, 1995.

ROCHA, Patrícia Rodrigues; TODESCO, Carla Alexandra do Amaral. Programa de educação de rua: Fundação Projeto Travessia. Trabalho apresentado no $1^{\circ}$ Congresso Internacional de Pedagogia Social, março 2006.

SERON, Paulo César. Destituição do poder e drogadição: a psicologia e as intervenções familiares. In: CONGRESSO INTERNACIONAL DA PSICOLOGIA DA UEM: Psicologia e direitos humanos: formação, atuação e compromisso social, VI, 2015, Maringá - PR. Anais... Maringá, 2015. Disponível em: <http://cipsi.vwi.co.br/anais/publicacoes/letter/d>. Acesso em: 06 abr. 2017.

SILVA, André Ricardo Fonsêca. Impacto do programa bolsa família na luta fundiária da comunidade quilombola da Caiana dos Crioulos: um estudo sobre cidadania. Tese - Programa de Pós-Graduação em Políticas Públicas e Formação Humana, da Universidade do Estado do Rio de Janeiro - UERFJ, Rio de Janeiro, 2015. 
STRAPASSON, Karoline; PAMPLONA, Danielle Anne. O direito em contradição: direitos humanos, atuação estatal e população em situação de rua. Revista Política Pública, São Luís, v. 18, n. 2, p. 439-456, jul./dez. 2014.

UNESCO. A Comissão Futuros da Educação da Unesco apela ao planejamento antecipado contra o aumento das desigualdades após a COVID-19. Paris: Unesco, 16 abr. 2020. Disponível em: https://pt.unesco.org/news/comissaofuturos-da-educacao-da-unesco-apela-ao-planejamento-antecipado-o-aumento-das. Acesso em: 4 jun. 2020.

UNICEF. Covid-19: are children able to continue learning during school closures? a global analysis of the potential reach of remote learning policies using data from 100 countries. https://www.unicef.org/brazil/media/10006/file/remote-learning-factsheet.pdf. Acesso em: 04/06/2021.

VASCONCELLOS, Marcos Antônio Sandoval de. Fundamentos de Economia. São Paulo: Saraiva, 2005.

VAZ, José Eduardo Parlato Fonseca. O Direito Social à Alimentação. Associação Brasileira de Direito Processual. 2010. 
Para publicar na revista Brasileira de Políticas Públicas, acesse o endereço eletrônico www.rbpp.uniceub.br

Observe as normas de publicação, para facilitar e agilizar o trabalho de edição. 